\title{
Political Overconfidence Inhibits the Effectiveness of Inoculations Against Misperceptions
}

\author{
Ian G. Anson \\ Associate Professor, \\ University of Maryland, Baltimore County \\ 1000 Hilltop Cir., 305 PUP \\ Baltimore, MD 21250 \\ iganson@umbc.edu
}

October 12,2021

APSA Preprint Version

\begin{abstract}
Recent scholarship has revealed that many Americans overestimate the extent of their own political knowledge. In this study, I develop an experimental framework to examine whether political overconfidence leads Americans to defend political misperceptions. Politically overconfident Americans, who suffer from the "double bind" of ignorance described by the Dunning-Kruger Effect, are expected to resist the effects of corrective inoculations against misperceptions. In two survey experiments, I measure political overconfidence, and assess its effects on skepticism towards five common misperceptions. In one study, I randomly expose respondents to an inoculation message, and observationally assess the effects of political overconfidence on the inoculation's effectiveness. In a second study, I experimentally manipulate overconfidence itself, by exposing a random subset of respondents to an objective assessment of their political knowledgeability before random exposure to an inoculation. Together, the results show that corrective inoculations can reduce support for misperceptions. However, among the politically overconfident, these treatments are ineffective. The finding that overconfidence dampens receptivity to corrective information suggests a major challenge for fact-checkers and science communicators in modern democratic politics. While for most people, consensus is a useful corrective, some overconfident Americans believe themselves to be wiser than the crowds.
\end{abstract}


In 1981, Ola Svenson conducted a study of mass driving competence as part of a broader investigation of automobile safety culture (Svenson 1981). In a surprise to the early readers of the study (but perhaps not to seasoned commuters), most subjects believed themselves to be above average drivers. Since that time, psychologists have learned that this phenomenon extends far beyond the highway. From classrooms to boardrooms, from brokerages to hospitals, widespread overconfidence among poor performers can lead to suboptimal outcomes. Based on the namesake authors' investigations of overconfidence in educational settings, such misplaced self-appraisals are commonly labeled the "Dunning-Kruger Effect" (e.g., Kruger and Dunning 1999; Hodges, Regehr, and Martin 2001). According to the Dunning-Kruger thesis, poor performers overstate their skills because they do not understand the nature of their deficient performance. Lacking knowledge of the "unknown unknowns" that yield more cautious selfappraisals among the skilled, the overconfident are notoriously resistant to correctives.

Overconfidence extends to the realm of political behavior. Recent studies have revealed that political overconfidence, or an over-estimation of one's skill in comprehending political phenomena, is widespread (e.g., Anson 2018; Anspach, Jennings, and Arceneaux 2019; Graham 2020; Ortoleva and Snowberg 2015). Americans may not know very much about political institutions, the actors that inhabit them, or political events, but on average, they believe that they know a great deal. So too do Americans overstate their ability to spot fake news (Lyons et al., 2021). The result is a tendency towards political polarization, and a lack of interest in the acquisition of additional political knowledge. This is because Americans who (inaccurately) think they know a lot about politics are quick to adopt strong partisan and ideological commitments. However, the consequences of this overconfident worldview for political knowledge and misinformation are still not fully understood. 
The goal of this study is to determine whether political overconfidence disrupts efforts to correct misperceptions among the American public. A burgeoning literature on misperceptions and factual inaccuracies in public opinion shows that these errors can be difficult to correct or combat (e.g., Jerit, Barabas, and Bolsen 2006; Nyhan and Reifler 2010; Thorson 2016; Wood and Porter 2019). Some recent efforts have nevertheless found success in reducing individuals' willingness to support falsehoods using specialized treatments (e.g., Nyhan and Reifler 2015; Nyhan et al. 2019; Bode and Vraga 2018). However, the relative effectiveness of such interventions on individuals with overconfident self-appraisals is not yet well understood.

While partisan motivated reasoning is often viewed as a prime culprit for the immutability of political misperceptions (e.g., Kunda 1990), overconfidence represents a second, underexplored determinant (but see Graham 2020; Lyons et al. 2021). I argue that this concept helps to explain why many Americans are unwilling to update their incorrect beliefs. Because overconfident individuals experience over-placement, or an over-ranking of their own political knowledge vis-a-vis an imagined population, they are more willing to discount messengers of contradictory information in favor of their own priors. As a result, many Americans will dismiss seemingly uncontroversial facts and ideas in favor of their own unpopular, but plausible, ideas.

In the present study, I examine the effects of corrective inoculation messages on subjects' support for factual misperceptions (e.g., Carnahan et al. 2021; Lewandowsky and van der Linden 2021). In two survey experiments, I measure respondents' levels of political overconfidence by comparing their objective score on a political knowledge quiz to their perceived performance. Next, I randomly expose subjects to inoculation vignettes which report on the (fictional) opinions of a sample of other survey respondents (Rothschild and Malhotra 2014). The vignettes purport to show that among 1,000 other survey respondents, large majorities rated five politically 
relevant falsehoods as "false." These messages are designed to reveal the unpopularity of respondents' misperceptions, generating a useful heuristic for skeptical evaluations of misinformation (Vraga and Bode 2018). These interventions are followed by survey items which rate subjects' skepticism towards the same misperceptions.

In Study 1, I examine whether overconfidence limits the effectiveness of the inoculation treatment in a large-scale observational setting. However, in Study 2, I causally identify the effect of overconfidence on treatment uptake by directly manipulating respondents' political overconfidence. I do this by exposing a random subset of respondents to their own results on the political knowledge quiz, along with a rating scale which compares their score to the real scores of around 1,000 other survey respondents (Schlösser et al. 2013). Next, I randomly expose subsets of both groups to the inoculation treatment from Study 1, resulting in a 2x2 design that subdivides respondents into a pure control group, a confidence-adjusted group, an inoculated group, and an inoculated and confidence-adjusted group.

The results of both studies show that overconfident respondents are less sensitive to informational cues than those who accurately assess their political knowledge. Nonoverconfident respondents across the ideological and partisan spectrum reduce their support for misperceptions when inoculated. However, the politically overconfident are relatively unaffected by the direction of public opinion. The notion that a large swath of the public is "ignorant of its own ignorance" (Kruger and Dunning 1999) helps to explain the relatively impervious nature of common (and potentially deleterious) political misperceptions in an era of polarization and declining institutional trust.

\section{Sources of Political Misperceptions}


Americans are susceptible to a wide variety of factual misperceptions. Much of the recent literature on misperceptions has focused on partisan and ideological drivers, as partisan motivated reasoning causes Republicans and Democrats to adopt party-congenial worldviews (e.g., Bolsen, Druckman, and Cook 2014; Kunda 1990). Examples include economic topics such as debt ownership, jobs, tax cuts and wealth accumulation, the solvency of Social Security, and drug prices (e.g., Bartels 2009; Kahne and Bowyer 2017; Nyhan and Reifler 2010; Schaffner and Roche 2016; Thorson 2016; Wood and Porter 2019). Motivated reasoning can cause party adherents to adopt contrasting sets of factual perceptions, even when exposed to the same new information. Salient party cues, relayed by trusted elites to the public, lead partisans to filter and interpret information to support congenial narratives (e.g., Kahan 2015; Slothuus, Leeper, and Druckman 2018; Taber and Lodge 2006).

Faults in Americans' perceptions can also emerge due to deficits in basic knowledge. Among other examples, scholars working at the intersection of political science and public health have highlighted the recent spread of misperceptions related to vaccines, smoking, stem cell research, and the healthcare industry (e.g., Berinsky, Huber, and Lenz 2012; Nyhan and Reifler 2010; Nyhan et al. 2014; Motta, Callaghan, and Sylvester 2018; Pasek, Sood, and Krosnick 2015). ${ }^{1}$ Even deeply conspiratorial beliefs about reality can be easily supported by audiences with little prior knowledge of science, technology, and politics (e.g., Uscinski, Klofstad, and

\footnotetext{
${ }^{1}$ Misperceptions on crime, the Death Penalty, climate change anthropogenesis, Israeli settlements, genetically modified foods, immigration, and the solar industry have also been studied (Benegal 2018; Gvirsman 2015; Kull and Ramsay 2000; Nyhan and Reifler 2010; Weeks 2015; Weeks and Garrett 2014; Wood and Porter 2019.)
} 
Atkinson 2016). So too can pervasive, incorrect beliefs about American politics stem from a kind of "folk wisdom" acquired through interpersonal communication, primary education, and the press. Thorson (2016) points to examples in this realm such as the size of the national debt, the amount of U.S. foreign aid provided to other nations, and the role and responsibilities of the president vis-a-vis the other branches of government.

\section{Political Overconfidence}

I argue that the political misperceptions studied in prior research can also occur due to the psychological phenomenon of overconfidence. In contrast to basic knowledge deficits or the effects of partisan motivated reasoning, individuals with overconfident self-appraisals may be said to suffer from the so-called "Dunning-Kruger Effect" (Kruger and Dunning 1999). In this framework, the ignorance of one's own ignorance drives a negative feedback loop of poor performance. Across a variety of tasks, relatively low-skilled performers have been found to overestimate the success of their performance, until informed of their relative standing (e.g., Hodges, Regehr, and Martin 2001; Dunning, Heath, and Suls 2004; Sheldon, Dunning, and Ames 2014; but see Krajc and Ortmann 2008). Self-perceptions of competence are often incorrect, leading to seemingly irrational behavior.

Political overconfidence is a special case of the Dunning-Kruger phenomenon (Anson 2018). While little is known about the origins of political overconfidence, it seems plausible that this stance is associated with a broader attitude of heightened self-regard (Moore and Schatz 
2017). ${ }^{2}$ Regardless of its relationship to other kinds of self-appraisals, it is known to have important consequences for ideological and partisan commitments (Ortoleva and Snowberg 2015a, 2015b).

Only rarely has the phenomenon been conceptualized from the perspective of Dunning and Kruger's “double bind of incompetence.” Anson (2018) conceptualizes political overconfidence as over-placement: the extent to which individuals believe they have "above average" political knowledge relative to peers (Kruger and Dunning 1999). ${ }^{3}$ Results of this study show that over-placed Americans rely heavily on partisan heuristics to judge the competence of others, and that the increased salience of partisan identities leads Americans to over-place more intensely. Together, these findings speak to the broad importance of political overconfidence for political attitudes, partisan commitments, and interpersonal communication.

Existing work has occasionally examined the relationship between overconfidence and susceptibility to misperceptions. Graham (2020) demonstrates that confident responses to

\footnotetext{
${ }^{2}$ One corollary question related to political overconfidence is whether this concept really maps on to an overall trait of general overconfidence in all areas of life. Ortoleva and Snowberg (2015a) begin to investigate this possibility by examining economic perceptions and general knowledge questions as sources of overconfidence, finding that the two are relatively interchangeable as predictors of political outcomes. While this is a question best left to future papers, it stands to reason that the generally overconfident may be especially likely to harbor political overconfidence, and vice versa.

${ }^{3}$ Alternative conceptualizations of overconfidence include over-precision and over-estimation (e.g., Moore and Schatz 2017).
} 
perceptual survey questions tend to be more accurate than less-confident ones. This finding appears to occur regardless of the strength or direction of respondents' partisan attachments. Lyons et al.'s (2021) important recent study also shows that fake news susceptibility increases as respondents over-state their own skills in navigating the media environment. Despite these advances, it currently remains unclear how and whether overconfidence changes individuals' willingness to correct themselves when exposed to inoculations to misinformation.

\section{Why Overconfidence Strengthens the Durability of Misperceptions}

Combating political misperceptions is a difficult task in the contemporary information environment. However, Dunning and Kruger's (1999) concept of over-placement, or a misguided sense of superior knowledgeability vis-a-vis an imagined peer group, offers a theoretical explanation. $^{4}$

According to the Dunning-Kruger framework, the overconfident experience a so-called "double bind of incompetence," in which they lack the ability to understand their need for improvement (Sheldon et al. 2014). Corrective feedback normally helps poor performers understand their performance deficit, leading to revised behaviors and more grounded selfappraisals. In some educational studies, overconfident students successfully responded to correctives (e.g., Dunning 2011). However, in another study, overconfident subjects who performed poorly on a measure of emotional intelligence refused to seek out resources for improvement after discovering they were relatively unskilled (Helzer and Dunning 2012). In this

\footnotetext{
${ }^{4}$ See also the continued influence effect (Ecker et al. 2011).
} 
case, overconfident performers resisted feedback and did not engage in self-reflection about the causes of their failure.

Beyond the effects of poor performance alone, such results indicate that the "double bind of ignorance" experienced by the overconfident can sometimes increase resistance to correction. This is because, paradoxically, the Dunning-Kruger effect causes poor performers to assume that corrective information is not valuable or necessary. However, this premise has not yet been tested in a political context.

Over-placement stands out as a potential predictor of resistance to corrections due to its fundamentally comparative or other-regarding nature. Information processing theories assert that individuals weigh their own priors against new, potentially conflicting information. Once an over-placed individual develops minimal priors about a subject, conflicting facts will be met with heavier than normal resistance. Like the phenomenon of over-precision (Ortoleva and Snowberg 2015), the over-placed individual assumes that they have previously gathered the highest-quality information possible. They will assume that in the past, their superior information-gathering skills led them to learn the most vital, important, and accurate information about political topics.

But in addition, the over-placed individual will overlook external heuristic cues that support learning in complex environments (e.g., Slothuus et al. 2018). In modern political discussion networks, corrective cues might come from family members, friends, coworkers, or official sources. These cues might be discounted if one perceives oneself to be more credible than others. A strong "sense of self," in this case manifested through over-placement, can lead individuals to rapidly strengthen their beliefs and commitments after gaining only a cursory 
amount of information about a political topic (Wolak and Stapleton 2019). ${ }^{5}$ The result is a kind of path dependency, in which new information is supported if it accords with one's priors, and is resisted if it conflicts.

\section{Consensus Messages: Inoculating Against Misperceptions}

Rationally ignorant Americans rely on basic cues to navigate modern political communication. Sometimes these cues come in the form of statements from official sources, like those included as interventions in Nyhan and Reifler's (2015) important study of misperceptions. But in many cases, citizens also attend to the popularity of messages and ideas to contextualize the value and meaning of new information (e.g., Bond et al. 2017; Messing and Westwood 2014). These cues are often conveyed to users of social media and online news websites as tallies of other users' reactions (Dvir-Gvirsman 2019; Marwick and Boyd 2011).

Consensus messages are inoculations designed to help users understand the relative unpopularity of their beliefs and attitudes. For example, in van der Linden et al.'s (2017) study, inoculated subjects saw a graphic claiming that $97 \%$ of scientists agreed about climate change's human causes. In this same vein, landslide results from public opinion polls can convince

\footnotetext{
${ }^{5}$ Overconfidence and its subtypes may be related to the concept of internal political efficacy, though the two are not the same (e.g., Lassen and Serritzlew 2011; Preece 2016). In a classic formulation, internal efficacy is evaluated using a survey item which asks, "I think I am better informed than most people about politics" (Craig, Niemi, and Silver 1990). Unlike self-reported internal political efficacy measures, over-placement is estimated as the objectively measured gap between one's real and imagined political competence.
} 
audiences to revise their attitudes (e.g., Searles, Ginn, and Nickens 2016). Polls can help audiences gain information about the relative popularity of their own beliefs, leading to revised levels of enthusiasm towards candidates and political objects (Rothschild and Malhotra 2014).

Whether rendered by social media posts or through in-person communication, consensusbased inoculation messages can convey the idea that misinformed beliefs are unpopular (Lewandowsky and van der Linden 2021). However, political overconfidence may interfere with receptivity to consensus messages. Inoculation messages generated by friends, family members, neighbors, polling results, and official sources are all likely to be met with resistance when presented to over-placed individuals. The over-placed individual will rate their own prior attitudes as unassailable, and display skepticism towards the claims of others, regardless of those claims' popularity. Thus, inoculation messages will be met with skepticism among the overconfident, despite the overconfident individual's lack of objective political knowledge.

\section{Expectations}

This line of reasoning leads to the expectation that political overconfidence will depress the effects of a consensus inoculation message in a survey experimental setting. This expectation is stated below as H1:

- H1. Politically overconfident individuals will exhibit decreased responsiveness to a misinformation inoculation relative to those with accurate self-appraisals.

This hypothesis regards political overconfidence as an exogenous independent variable predicting inoculation responsiveness. However, because over-placement is likely strongly 
correlated with several other relevant political and social predictors of misinformation susceptibility, H1 poses an empirical challenge. To that end, I next introduce two specialized experimental research designs.

\section{Two Inoculation Experiments}

From December 20-21, 2019, I reached a national sample of adults $(\mathrm{N}=1,017)$ using the Amazon MTurk platform (hereafter Study 1). ${ }^{6}$ Respondent qualification criteria included a 95\% MTurk approval rate and United States place of residence. From September 22-23, 2021, following a pre-registered study design, ${ }^{7}$ I reached a second national sample $(\mathrm{N}=1,209)$ using the Lucid Theorem marketplace (hereafter Study 2). See Coppock and McLellan (2019) for an assessment of this second data source.

\footnotetext{
${ }^{6}$ While MTurk samples are not demographically or politically representative of the broader U.S. population, they are notably attentive, and are therefore less likely to engage in satisficing behavior on the knowledge tasks described in the experimental protocol below (e.g., Hauser and Schwartz 2016). For this reason, MTurk was preferred over other survey samples of comparable cost.

${ }^{7}$ Pre-registration was completed via osf.io. Further details are included in the Supplementary Information.
} 
Fig. 1. Experimental Design, Studies 1 and 2

Study 1

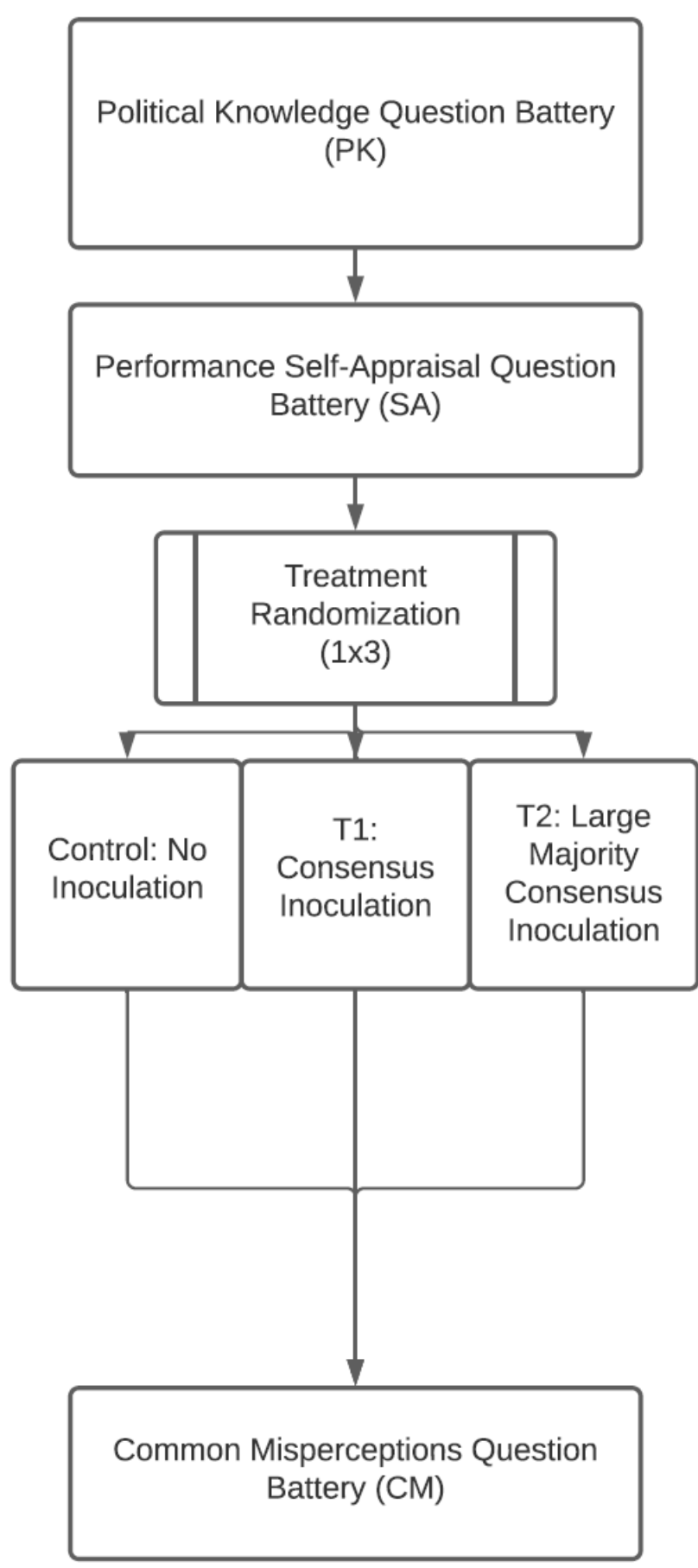

Study 2

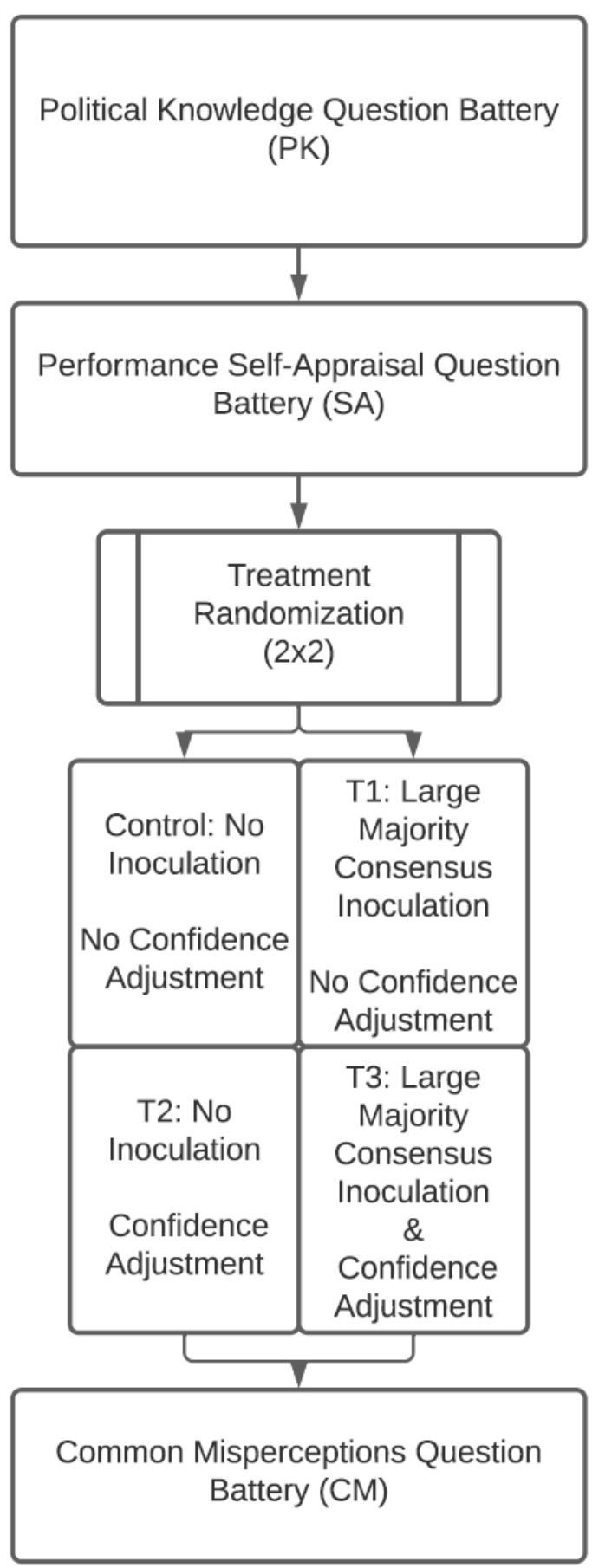




\section{Pre-Treatment Items}

The experimental protocols for both studies are detailed in Fig. 1. In each Study, the protocol began with the collection of basic demographics and the assessment of general political knowledge. A political knowledge battery (hereafter "PK battery") consisted of an additive political knowledge scale designed and validated by Anson (2018). The PK battery includes political knowledge items related to American political institutions, current events, and political ideology. The questions were designed to be relatively difficult to answer correctly, as suggested by prior literature on the Dunning-Kruger effect. The PK battery was followed by a selfappraisal battery (hereafter "SA battery") which asked respondents to evaluate their selfplacement (on a percentile scale relative to "others who had taken the test") and their performance (on a scale from "poor" to "excellent"). See the SI for question wording and scale validation.

\section{Study 1: Experimental Conditions}

Respondents in Study 1 were next randomly assigned to one of three treatment groups. Treatments provided inoculation messages that took the form of survey results (Rothschild and Malhotra 2014). Respondents were told that "last month, we asked around 1,000 respondents like you to rate these items as true or false." Respondents next saw a table containing five common misperceptions, and the percentage of survey respondents who rated each statement as "false." See the SI for full treatment descriptions, and Table 1 (below) for a list of these items. The treatment conditions tested two versions of this inoculation message with varying message strength. In T1, majorities of the fictional sample (62-71\%) rejected each statement as false. In 
T2, larger majorities (88-94\%) of fictional respondents rated each statement as false. A third group of respondents were assigned a Control condition with no inoculation message. ${ }^{8}$

\section{Study 2: Experimental Conditions}

In Study 2, respondents were randomly assigned to one of four conditions in a $2 \times 2$ experimental design. Respondents in T1 received the "large majority" inoculation message described above, with $88-94 \%$ of fictional survey respondents rating each misperception as false. Those in $\mathrm{T} 2$ received a message describing their results on the PK battery, which I refer to as a "Confidence Adjustment" task (Helzer and Dunning 2012). Respondents in T3 received both the "Confidence Adjustment" task and the large majority inoculation message. The study also includes a pure Control condition, in which respondents saw neither of these two messages.

The "Confidence Adjustment" task was designed to both increase respondents' awareness of their real performance on the knowledge battery, and to help respondents know where they stood vis-à-vis their peers. Ultimately, this treatment is designed to reduce political overconfidence in the treatment groups that received it. ${ }^{9}$ To that end, the "Confidence

\footnotetext{
${ }^{8}$ The inoculation cues were designed to avoid the potential for experimenter effects. They also avoid potential confounds associated with source cueing (e.g., Chaiken 1980). Information from official government sources or prominent media sources may convey different levels of credibility to respondents across the political spectrum.
}

${ }^{9}$ A manipulation check confirms that self-assessed political knowledge decreased in the groups receiving the Confidence Adjustment task by around 4 percentage points on average $(p<0.01)$. Among the initially overconfident, this decline was roughly 7 percentage points $(p<0.01)$. 
Adjustment" task showed respondents a table indicating their performance percentile based on the number of questions they had correctly answered in the PK battery. Respondents were then asked to report their own performance ("below average," "average," or "above average") in an attention-check style survey item. This treatment was therefore designed to dampen overconfident respondents' over-placement as well as the overestimation of their baseline political knowledge. ${ }^{10}$

\section{Dependent Variables: Misperceptions and their Corrections}

In the next phase of both Studies 1 and 2, all respondents evaluated a five-item question battery tapping common misperceptions (hereafter the "CM battery"). The questions in the $\mathrm{CM}$ battery were the same items listed in the inoculation treatments. The topics contained in the $\mathrm{CM}$ battery are listed in Table 1 below, alongside information identifying the misperception and its direction of partisan congeniality. The topics were derived from existing literature on misperceptions, as indicated in the rightmost column of the table.

\footnotetext{
${ }^{10}$ Because all respondents in this condition learn about their score on the political knowledge battery, this treatment also reveals to the under-confident the extent of their exceptionalism. While the effects of this phenomenon are unclear given the present theory, under-confident appraisals are far more rare than overconfident ones and are unlikely to pose a threat to validity.
} 
Table 1. List of Five Common Misperceptions Included in Inoculation Messages and Study DV Battery

\begin{tabular}{|c|c|c|}
\hline Topic & Misperception & Source \\
\hline U.S. Debt & China owns the majority of U.S. government debt & $\begin{array}{l}\text { Wood \& Porter } \\
\text { (2019) }\end{array}$ \\
\hline Foreign Aid & The Federal government contributes $18 \%$ of the Federal & Kull \& Ramsey \\
\hline Contributions & budget to aid to foreign nations & $(2000)$ \\
\hline Fictional & The U.S. Department of Special Programs had an & Wood \& Porter \\
\hline Bureaucracy & operating budget of $\$ 41 \mathrm{~b}$ in 2018 & $(2019)$ \\
\hline Social Security & By 2035 , there will be no money left to pay out Social & Jerit \& Barabas \\
\hline Solvency & Security entitlements to retirees & $(2006)$ \\
\hline Crime & $\begin{array}{c}\text { Violent crime in the U.S. has increased over the past ten } \\
\text { years }\end{array}$ & $\begin{array}{l}\text { Weeks \& Garrett } \\
\text { (2014) }\end{array}$ \\
\hline
\end{tabular}

\section{Methods}

To derive appropriate statistical tests of H1, I rely upon OLS regression models. The DV in these models is a continuous scale measuring skepticism towards the five misperceptions shown in Table 1. For each item, respondents were asked to evaluate the statement's accuracy on a scale from 1 (not at all accurate) to 5 (very accurate). the DV measure sums these responses and scales them to $[0: 1]$.

In Study 1, I construct regression models which include treatment effects (described in Fig. 1), a measure of political overconfidence, and their interactions. I operationalize political overconfidence through a "Confidence Accuracy" score, which measures the difference between 
respondents' perceived performance quintile (reported in the SA battery), and the quintile in which they scored on the PK battery. ${ }^{11}$ A score of 4 on this variable indicates a respondent was extremely overconfident, having rated their performance in the top quintile, while scoring in the bottom quintile. A score of 0 indicates an accurate self-perception, in which the respondent's perceived quintile was the same as their objective performance quintile. Correspondingly, a score of -4 indicates an extremely under-confident self-appraisal. To facilitate the interpretation of coefficients, I rescale the Confidence Accuracy score to take a range of $[-1,1]$.

Study 1 therefore models skepticism towards misperceptions in the following manner:

I also examine $\mathbf{H 1}$ in Study 1 in the presence of additional control variables. A full model specification accounts for objective political knowledge, which is fairly, but not highly, correlated with self-appraisals $(\mathrm{r}=0.22)$. Political knowledge is also known to be inversely associated with satisficing on online survey instruments, a phenomenon which can dampen the strength of a treatment response (e.g., Berinsky, Margolis, and Sances 2014). To account for this possibility, I include the logged time it took to complete the knowledge items as a measure of speeding (a proxy for survey satisficing). These design decisions are intended to better model the independent effects of overconfidence on misperception corrections.

\footnotetext{
${ }^{11}$ Lyons et al. (2021) discuss several possible operationalizations of overconfidence, finding similar effects for differencing methods and more complex modeling strategies. I favor the differencing transformation for its simplicity.
} 
In Study 2, I assess $\mathbf{H 1}$ in a purely experimental context, by assessing the treatment effects of each experimental condition relative to the Control. To that end, I compare the effectiveness of the inoculation message under two conditions: in the presence of the Confidence Adjustment task (T3 vs. Control), and in the absence of the Confidence Adjustment task (T1 vs. Control). Ultimately, I expect the inoculation to be more efficacious when the Confidence Adjustment task is included, meaning I also test the T3 vs. T1 contrast. To assess these expectations, I construct the following OLS regression model:

Skepticism $=\alpha+\beta 1($ Inoculation $)+\beta 2($ Conf. Adj. $)+\beta 3($ Inoculation $*$ Conf. Adj. $)+\varepsilon$

While the effects of the Confidence Adjustment treatment on the results are strongest among the overconfident (see the SI for details), to avoid adding covariates to an otherwise straightforward experimental design, in the main text I present the results of the above regression model for all respondents in the Study 2 sample (both overconfident and not overconfident).

\section{Results}

Before examining results pertaining to $\mathbf{H 1}$, it is instructive to visualize the distribution of political overconfidence. To do this I replicate a graphic first designed by Kruger and Dunning (1999), which plots objective task performance against perceived task performance for both Study 1 and Study 2 (see also Anson 2018; Lyons 2021). Using the five-item PK battery as the basis for this assessment, I construct a graphic which plots the number of correct PK battery answers on the $\mathrm{x}$-axis (from 0 to 5 ). The $\mathrm{y}$-axis measures perceived and objective task performance as expressed by sample percentiles. Thus, as seen in Fig. 2 below, the graph shows 
two curves in each facet: the actual performance percentile of respondents who took the test (indicated by a solid line), and the percentile in which respondents thought they placed (indicated by a dashed line connecting to points with $95 \%$ Confidence Intervals).

Fig. 2. Observed vs. Perceived Performance on a Political Knowledge Quiz, Studies 1 and 2

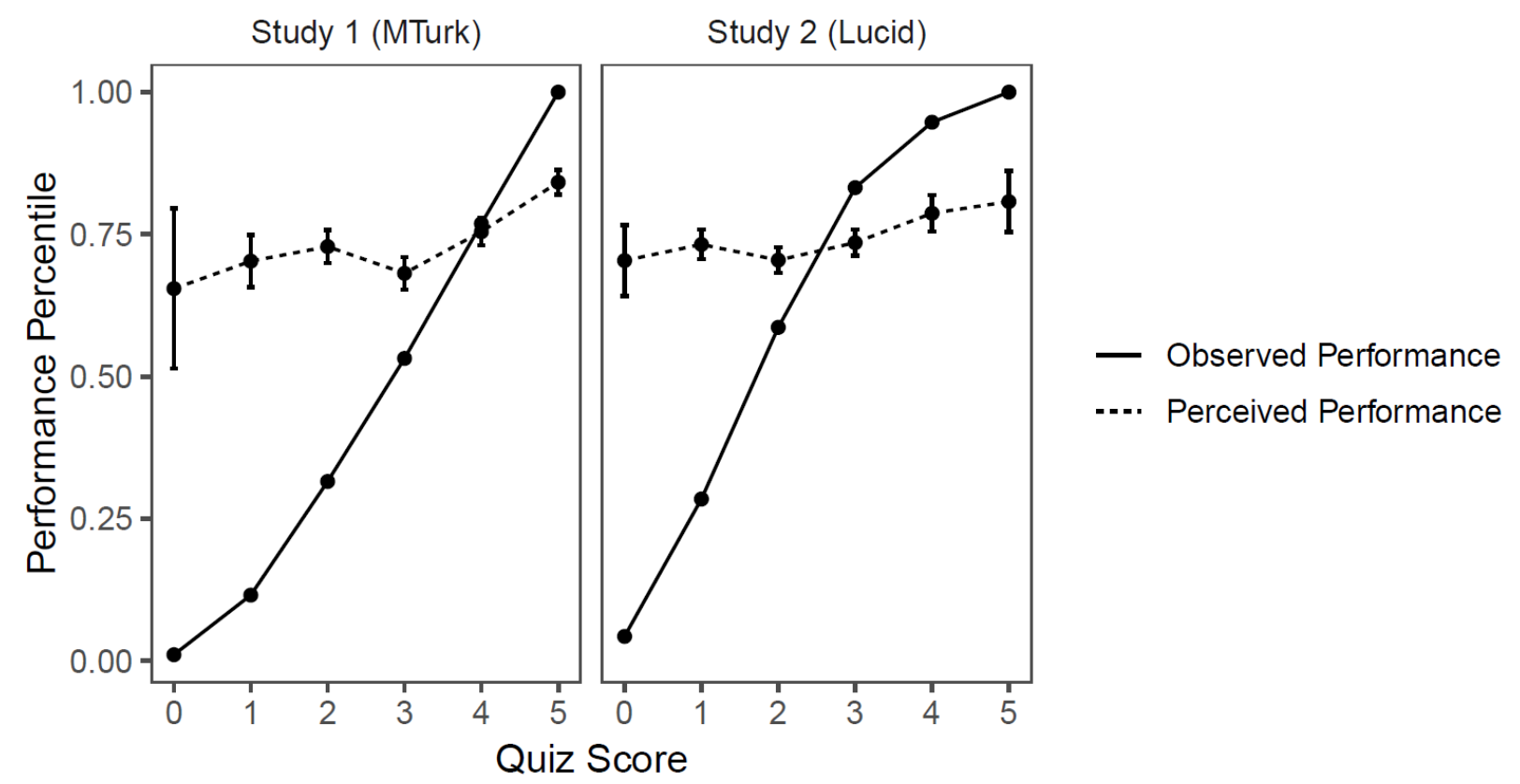

As is immediately apparent from Fig. 2, the average respondent over-estimates their performance relative to peers in both Studies 1 and 2 in remarkably similar ways. While the dashed line has a shallow positive slope in both Studies (meaning the best performers said they did somewhat better on average than the worst), this slope is not nearly steep enough to reflect objective performance. In Study 1, for example, only around $11 \%$ of respondents answered 1 or fewer questions right, putting these individuals far below average. However, those respondents who scored 0 on the quiz thought they were, on average, in the 65 th percentile. Those who got one out of the five questions right thought they were in the 70th percentile on average- - better 
than more than 2/3 of their peers. The same phenomenon occurs in Study 2, as those scoring 0 on the quiz placed themselves in the $70^{\text {th }}$ percentile, and those scoring 1 placed themselves in the $73^{\text {rd }}$ percentile on average. Overconfidence, as measured by the discrepancy between perceived and objective performance on a political knowledge quiz, is widespread in both samples.

\section{Study 1: Results}

Next, I examine the evidence for $\mathbf{H 1}$ in Study 1. To do this I first present Table 2, which shows the results of four OLS regression models predicting skepticism towards misperceptions. 
Table 2. Results of OLS Regression Models Predicting Skepticism towards Five Common Misperceptions [0:1]

\begin{tabular}{|c|c|c|c|c|}
\hline & \multicolumn{4}{|c|}{ Dependent variable: } \\
\hline & \multicolumn{4}{|c|}{ Skepticism [0:1] } \\
\hline & (1) & (2) & (3) & (4) \\
\hline T1: Consensus Inoculation & $\begin{array}{l}0.059^{* * *} \\
(0.015)\end{array}$ & $\begin{array}{l}0.070^{* * * *} \\
(0.016)\end{array}$ & $\begin{array}{l}0.072^{* * * *} \\
(0.016)\end{array}$ & $\begin{array}{l}0.070^{* * *} \\
(0.016)\end{array}$ \\
\hline $\begin{array}{l}\text { T2: Large Majority } \\
\text { Consensus Inoculation }\end{array}$ & $0.049^{* *}$ & $0.066^{* * *}$ & $0.072^{* * *}$ & $0.071^{* * *}$ \\
\hline & $(0.015)$ & $(0.016)$ & $(0.016)$ & $(0.016)$ \\
\hline Confidence Accuracy [-1:1] & & $\begin{array}{c}0.010 \\
(0.029)\end{array}$ & $\begin{array}{l}0.142^{* * * *} \\
(0.033)\end{array}$ & $\begin{array}{l}0.138^{* * *} \\
(0.033)\end{array}$ \\
\hline Political Knowledge [1:5] & & & $\begin{array}{c}0.049^{* * * *} \\
(0.007)\end{array}$ & $\begin{array}{c}0.049^{* * *} \\
(0.007)\end{array}$ \\
\hline $\begin{array}{l}\text { Knowledge Battery } \\
\text { Completion Time }(\log )\end{array}$ & & & & $\begin{array}{l}-0.018^{*} \\
(0.008)\end{array}$ \\
\hline $\mathrm{T} 1 *$ Confidence Accuracy & & $\begin{array}{l}-0.107^{* *} \\
(0.041)\end{array}$ & $\begin{array}{l}-0.119^{* *} \\
(0.040)\end{array}$ & $\begin{array}{l}-0.117^{* *} \\
(0.040)\end{array}$ \\
\hline $\mathrm{T} 2 *$ Confidence Accuracy & & $\begin{array}{c}-0.134^{* * *} \\
(0.040)\end{array}$ & $\begin{array}{c}-0.142^{* * *} \\
(0.039)\end{array}$ & $\begin{array}{c}-0.140^{* * *} \\
(0.039)\end{array}$ \\
\hline Constant & $\begin{array}{c}0.450^{* * *} \\
(0.011)\end{array}$ & $\begin{array}{c}0.449^{* * * *} \\
(0.012)\end{array}$ & $\begin{array}{l}0.273^{* * *} \\
(0.027)\end{array}$ & $\begin{array}{l}0.344^{* * *} \\
(0.040)\end{array}$ \\
\hline Observations & 1,017 & 1,017 & 1,017 & 1,017 \\
\hline $\mathrm{R}^{2}$ & 0.016 & 0.045 & 0.093 & 0.098 \\
\hline Adjusted $\mathrm{R}^{2}$ & 0.014 & 0.040 & 0.087 & 0.091 \\
\hline Residual Std. Error & $\begin{array}{c}0.200(\mathrm{df}= \\
1014)\end{array}$ & $\begin{array}{l}0.197(\mathrm{df}= \\
1011)\end{array}$ & $\begin{array}{l}0.192(\mathrm{df}= \\
1010)\end{array}$ & $\begin{array}{c}0.192(\mathrm{df}= \\
1009)\end{array}$ \\
\hline F Statistic & $\begin{array}{c}8.358^{* * *}(\mathrm{df}= \\
2 ; 1014)\end{array}$ & $\begin{array}{c}9.517^{* * *}(\mathrm{df}= \\
5 ; 1011)\end{array}$ & $\begin{array}{c}17.205^{* * *}(\mathrm{df}= \\
6 ; 1010)\end{array}$ & $\begin{array}{c}15.606^{* * *}(\mathrm{df}= \\
7 ; 1009)\end{array}$ \\
\hline
\end{tabular}

Column 1 of Table 2 presents average experimental treatment effects. We see from this model that both the Consensus Inoculation (T1) and the Large Majority Consensus Inoculation 
(T2) appear to have had a substantial effect upon respondents' skepticism towards misperceptions in the aggregate. On average, respondents in T1 became around 6 percentage points more skeptical of misinformation compared to the Control group $(\mathrm{p}<0.01)$, while those in T2 saw their skepticism increase by around 5 percentage points $(\mathrm{p}<0.01)$. As both corrective cues had comparable effects, the results suggest that respondents are as attentive to inoculation messages from simple majorities as much as they are attentive to large majorities. Together, these results indicate that the treatments were effective in reducing misperception adherence on average.

Column 2 of Table 2 describes how political overconfidence conditions this average treatment effect. Because the Confidence Accuracy variable ranges from -1 to 1 , the coefficient for this variable denotes a shift from an accurate self-appraisal ( 0 on the scale) to a highly overconfident self-appraisal ( 1 on the scale). We see from this model that in the baseline condition, overconfidence is associated with only a small shift in skepticism (a 1 percentage point increase; $p=0.72$ ). However, respondents' overconfidence substantially interacts with both the $\mathrm{T} 1$ and the $\mathrm{T} 2$ treatment effects - providing evidence in support of H1. The interactive effect for T1 and Confidence Accuracy yields a decline in skepticism of almost 11 percentage points ( $p$ $<0.01$ ), fully counteracting (and even exceeding in magnitude) the positive treatment effect of T1. A similar negative effect is observed in the interaction between Confidence Accuracy and T2: moving from an accurate to an overconfident self-appraisal decreases skepticism in this group by 13.4 percentage points $(p<0.001)$.

These patterns persist when controlling for political knowledge and a measure of survey satisficing. Column 4 in Table 2 shows the results of a model with both variables included. The results indicate that while political knowledge $(\beta=0.049, p<0.001)$ and satisficing $(\beta=-0.018$, 
$p<0.05$ ) both predict skepticism towards common misperceptions, the interactive effects between T1 and T2 and the Confidence Accuracy measure continue to dampen the baseline treatment effects. Political overconfidence reduces skepticism by roughly 11.7 percentage points in the $\mathrm{T} 1$ treatment condition $(p<0.01)$ and by roughly 14 percentage points in the $\mathrm{T} 2$ treatment condition $(p<0.001)$, both in the presence of political knowledge and satisficing. These results again provide evidence in support of $\mathbf{H 1}$.

While these patterns are indicative of the idea that overconfidence dampens the effectiveness of inoculation messages, the results presented in Table 2 are ultimately observational in nature. Because Study 1 does not causally identify overconfidence, the above patterns are vulnerable to spuriousness, despite the inclusion of relevant control variables in Column 4 of Table 2. To assuage these concerns, I next present the results of Study 2, which experimentally manipulates both inoculation message exposure and political overconfidence.

\section{Study 2: Results}

In Study 2, I provide the results of an OLS regression model predicting skepticism towards five common misperceptions. This interactive model shows how skepticism varied in the presence of the inoculation message (T1), the Confidence Adjustment treatment (T2), and both messages (T3). Table 3, below, describes the study's results. 
Table 3. Results of OLS Regression Models Predicting Skepticism towards Five Common Misperceptions, Study 2

\begin{tabular}{lc}
\hline Large Majority Consensus Inoculation (T1) & -0.003 \\
Confidence Adjustment (T2) & $(0.013)$ \\
Confidence Adjustment* Inoculation (T3) & -0.005 \\
& $(0.013)$ \\
Constant & $0.039^{*}$ \\
& $(0.018)$ \\
Observations & $0.498^{* * *}$ \\
$\mathrm{R}^{2}$ & $(0.009)$ \\
Adjusted R & 1,193 \\
Residual Std. Error & 0.009 \\
F Statistic & 0.006 \\
\hline Note: & $0.155(\mathrm{df}=1189)$ \\
& ${ }^{*} \mathrm{p}<0.05^{* *} \mathrm{p}<0.01^{* * *} \mathrm{p}<0.001$
\end{tabular}

Surprisingly, the results in Table 3 show that the inoculation message alone had little effect on skepticism in the Study 2 sample. ${ }^{12}$ Relative to the Control condition, exposure to T1 was associated with a small decrease in skepticism towards misinformation of about a third of a percentage point $(p=0.81)$. We also see no significant effect for the Confidence Adjustment treatment (T2) relative to the Control $(\beta=-0.05, p=0.67)$. T2 was not expected to have an independent effect on skepticism towards misperceptions, as in this condition, respondents received no inoculation.

\footnotetext{
${ }^{12}$ It is unclear why the message was more effective in the Study 1 sample compared to the Study 2 sample, though differences in the samples' demographic compositions and attentiveness may be responsible.
} 
However, in the presence of the Confidence Adjustment treatment (T3), the inoculation message had a substantial positive effect on skepticism. We see in Table 3 that relative to the Control condition, T3 increased skepticism by roughly 3.9 percentage points $(p<0.05)$. This treatment-control contrast again provides evidence in support of H1. To further assess H1 I calculate the contrast between T1 (the inoculation condition) and T3 (the combined conditions). A significant contrast between these two conditions would also lend evidence to the notion that the inoculation is more effective when political overconfidence is dampened. Compared to T1, T3 increased skepticism towards misperceptions by roughly 4.2 percentage points $(p<0.05)$, yet again supporting the central assertion of $\mathbf{H 1}$.

While this effect holds in the full sample of respondents, it is likely that increased skepticism in the T3 condition is driven mostly by the revised appraisals of overconfident respondents. Indeed, a second model that includes only overconfident respondents ${ }^{13}$ showed a larger treatment effect (see the SI for full model specification). Among the overconfident alone, T3 increased skepticism towards misperceptions by roughly 4.4 percentage points relative to the Control $(\mathrm{p}<0.05)$, while T1 again yielded no significant effect $(\beta=0.001, p=0.93)$.

\footnotetext{
${ }^{13}$ The Confidence Accuracy variable described in Study 1 ranged from -1 to 1 , with 0 indicating an accurate appraisal of one's political knowledge, -1 indicating a highly underconfident appraisal, and 1 indicating a highly overconfident appraisal. In this model I only included respondents with Confidence Accuracy scores above 0 .
} 


\section{Discussion}

The results of Studies 1 and 2 show evidence that political overconfidence dampens Americans' willingness to correct their misperceptions. In response to consensus-based corrective inoculations, we see that politically overconfident Americans show no increased skepticism towards five common political misperceptions. In an observational setting, political overconfidence decreased the effectiveness of inoculations, even when controlling for political knowledge and survey satisficing. In an experimental setting, inoculations only had an effect on skepticism when political overconfidence had been successfully neutralized through the use of a specialized experimental treatment.

While partisan motivated reasoning and political knowledge deficits remain important directions for the study of misperceptions, the present results point to the idea that political overconfidence deserves scrutiny as an additional driver of factual inaccuracies in public opinion. While for most people, consensus is a useful corrective, some overconfident Americans believe themselves to be wiser than the crowds. This may be one relatively overlooked reason why efforts to correct misperceptions in the public are sometimes unsuccessful.

Study 2's Confidence Adjustment treatment also represents an advance in the study of political overconfidence. While such corrective cues have had mixed results in previous studies of the Dunning-Kruger Effect across context (e.g., Helzer and Dunning 2012), this study provides initial evidence that corrections can dampen individuals' overconfidence in the realm of political knowledge. However, it is difficult to imagine how such corrections can be implemented outside of a laboratory setting. The artificial nature of the Confidence Adjustment treatment speaks to the fact that Study 2's baseline conditions are far more accurate representations of the real world than is the confidence-adjusted condition. The "double bind" of 
ignorance described by the Dunning-Kruger effect is likely very difficult to overcome in realworld political settings. The evidence provided in support of $\mathbf{H 1}$ in this study indicates that political overconfidence likely poses an ongoing challenge to communicators hoping to better educate the public on political issues.

Much more work remains to better understand the complex relationships between overconfidence, political knowledge, and political misperceptions. In particular, it remains unclear how overconfidence conditions attempts to correct partisan congenial misperceptions. Misperceptions featuring explicit mentions of partisan elites, for example, may invoke a greater degree of motivated reasoning, further strengthening the deleterious effects of overconfidence on corrective efforts (Anson 2018). For instance, we might expect misperceptions of Barack Obama's birthplace or Donald Trump's 2020 election loss to be supported even when the overconfident have been disabused of their incorrect self-appraisals. Furthermore, it is likely that source cues matter in real-world inoculation attempts—especially partisan source cues.

While this study has examined overconfidence in two parsimonious settings as a proof of concept, analyzing its effects in social contexts represents an important direction for future research. The present study has examined corrective inoculations without the intervening effects of real-world social dynamics. As we know from existing studies of misperceptions, corrections and fact-checks can diminish misperceptions while failing to influence underlying political attitudes (Nyhan et al., 2019). Coupled with earlier findings that overconfidence leads to increasingly polarized beliefs (Ortoleva and Snowberg 2015a), the present findings point to a role for overconfidence in the defense of broader political worldviews. Overconfident individuals might defend extreme political attitudes and stances despite social pressure to rejoin the "sphere of consensus" (Hallin 1984). So too might they maintain support for these extremist ideologies in 
the face of concrete evidence that contradicts the misperceptions that support their worldview. In an era of online radicalization and persistent misperceptions, future investigations of political overconfidence are increasingly urgent. 


\section{Works Cited}

Anson, Ian G. 2018. "Partisanship, Political Knowledge, and the Dunning-Kruger Effect." Political Psychology 39 (5): 1173-92.

Anspach, Nicolas M., Jay T. Jennings, and Kevin Arceneaux. 2019. “A Little Bit of Knowledge: Facebook's News Feed and Self-Perceptions of Knowledge.” Research \& Politics 6 (1): 2053168018816189.

Bartels, Larry M. 2009. Unequal Democracy: The Political Economy of the New Gilded Age. Princeton University Press.

Benegal, Salil. 2018. "Overconfidence and the Discounting of Expertise: A Commentary." Social Science \& Medicine (1982) 213: 95.

Berinsky, Adam J, Michele F Margolis, and Michael W Sances. 2014. "Separating the Shirkers from the Workers? Making Sure Respondents Pay Attention on Self-Administered Surveys.” American Journal of Political Science 58 (3): 739-53.

Berinsky, Adam J. 2017. "Telling the Truth About Believing the Lies? Evidence for the Limited Prevalence of Expressive Survey Responding.” The Journal of Politics 80 (1): dx.doi.org/10.1086/694258.

Berinsky, Adam J., Gregory A. Huber, and Gabriel S. Lenz. 2012. “Evaluating Online Labor Markets for Experimental Research: Amazon.com's Mechanical Turk.” Political Analysis 20 (3): $351-68$.

Bode, Leticia, and Emily K. Vraga. 2015. "In Related News, That Was Wrong: The Correction of Misinformation Through Related Stories Functionality in Social Media." Journal of Communication 65 (4): 619-38.

—. 2018. "See Something, Say Something: Correction of Global Health 
Misinformation on Social Media." Health Communication 33 (9): 1131-40.

Bolsen, Toby, James N. Druckman, and Fay Lomax Cook. 2014. "The Influence of Partisan Motivated Reasoning on Public Opinion.” Political Behavior 36 (2): 235-62.

Bond, Robert M., Jaime E. Settle, Christopher J. Fariss, Jason J. Jones, and James H. Fowler. 2017. "Social Endorsement Cues and Political Participation." Political Communication 34 (2): $261-81$.

Bullock, John G, Alan S Gerber, Seth J Hill, Gregory A Huber, and others. 2015.

"Partisan Bias in Factual Beliefs About Politics." Quarterly Journal of Political Science 10 (4): $519-78$.

Carnahan, Dustin, Daniel E. Bergan, and Sangwon Lee. 2021. "Do corrective effects last? Results from a longitudinal experiment on beliefs toward immigration in the US." Political Behavior 43(3): 1227-1246.

Chaiken, S. (1980). Heuristic versus systematic information processing and the use of source versus message cues in persuasion. Journal of personality and social psychology, 39(5), 752.

Coppock, Alexander, and Oliver A. McClellan. 2019. "Validating the demographic, political, psychological, and experimental results obtained from a new source of online survey respondents." Research \& Politics 6(1): 2053168018822174.

Craig, Stephen C, Richard G Niemi, and Glenn E Silver. 1990. "Political Efficacy and Trust: A Report on the NES Pilot Study Items.” Political Behavior 12 (3): 289-314.

Dunning, David. 2011. "5 the Dunning-Kruger Effect: On Being Ignorant of One’s Own Ignorance." Advances in Experimental Social Psychology 44: 247-96.

Dunning, David, Chip Heath, and Jerry M. Suls. 2004. "Flawed Self-Assessment 
Implications for Health, Education, and the Workplace." Psychological Science in the Public Interest 5 (3): 69-106.

Dvir-Gvirsman, Shira. 2019. "I Like What I See: Studying the Influence of Popularity Cues on Attention Allocation and News Selection.” Information, Communication \& Society 22 (2): 286-305.

Ecker, Ullrich K.H., Stephan Lewandowsky, Briony Swire, and Darren Chang. 2011. "Correcting False Information in Memory: Manipulating the Strength of Misinformation Encoding and Its Retraction." Psychonomic Bulletin \& Review 18 (3): 570-78.

Goren, Paul, Christopher M Federico, and Miki Caul Kittilson. 2009. "Source Cues, Partisan Identities, and Political Value Expression.” American Journal of Political Science 53 (4): 805-20.

Gvirsman, Shira Dvir. 2015. “Testing Our Quasi-Statistical Sense: News Use, Political Knowledge, and False Projection.” Political Psychology 36 (6): 729-47.

Lewandowsky, Stephan, \& Van Der Linden, Sander. 2021. Countering misinformation and fake news through inoculation and prebunking. European Review of Social Psychology, doi: https://doi.org/10.1080/10463283.2021.1876983.

Hallin, D. C. (1984). The media, the war in Vietnam, and political support: A critique of the thesis of an oppositional media. The Journal of Politics, 46(1), 2-24.

Helzer, Erik G., and David Dunning. 2012. "Why and When Peer Prediction Is Superior to Self-Prediction: The Weight Given to Future Aspiration Versus Past Achievement. ” Journal of Personality and Social Psychology 103 (1): 38-53.

Hodges, Brian, Glenn Regehr, and Dawn Martin. 2001. "Difficulties in Recognizing One's Own Incompetence: Novice Physicians Who Are Unskilled and Unaware of It.” Academic 
Medicine 76 (10): S87-S89.

Jerit, Jennifer, and Jason Barabas. 2012. "Partisan Perceptual Bias and the Information Environment." The Journal of Politics 74 (3): 672-84.

Jerit, Jennifer, Jason Barabas, and Toby Bolsen. 2006. "Citizens, Knowledge, and the Information Environment.” American Journal of Political Science 50 (2): 266-82.

Kahan, Dan M. 2015. “The Politically Motivated Reasoning Paradigm, Part 1: What Politically Motivated Reasoning Is and How to Measure It." Emerging Trends in the Social and Behavioral Sciences: An Interdisciplinary, Searchable, and Linkable Resource, 1-16.

Kahne, Joseph, and Benjamin Bowyer. 2017. "Educating for Democracy in a Partisan Age: Confronting the Challenges of Motivated Reasoning and Misinformation." American Educational Research Journal 54 (1): 3-34.

Krajc, Marian, and Andreas Ortmann. 2008. “Are the Unskilled Really That Unaware? An Alternative Explanation.” Journal of Economic Psychology 29 (5): 724-38.

Kruger, Justin, and David Dunning. 1999. "Unskilled and Unaware of It: How Difficulties in Recognizing One's Own Incompetence Lead to Inflated Self-Assessments.” Journal of Personality and Social Psychology 77 (6): 1121-34.

Kull, Steven, and Clay Ramsay. 2000. "Elite Misperceptions of U.S. Public Opinion and Foreign Policy.” Decisionmaking in a Glass House: Mass Media, Public Opinion, and American and European Foreign Policy in the 21st Century, 95-110.

Kunda, Ziva. 1990. “The Case for Motivated Reasoning.” Psychological Bulletin 108 (3): $480-98$.

Lassen, David Dreyer, and Søren Serritzlew. 2011. “Jurisdiction Size and Local 
Democracy: Evidence on Internal Political Efficacy from Large-Scale Municipal Reform.” American Political Science Review 105 (02): 238-58.

Lyons, Benjamin A., Jacob M. Montgomery, Andrew M. Guess, Brendan Nyhan, and Jason Reifler. 2021. "Overconfidence in news judgments is associated with false news susceptibility." Proceedings of the National Academy of Sciences 118(23).

Marwick, Alice E., and Danah Boyd. 2011. "I Tweet Honestly, I Tweet Passionately: Twitter Users, Context Collapse, and the Imagined Audience." New Media \& Society 13 (1): $114-33$.

Messing, Solomon, and Sean J. Westwood. 2014. "Selective Exposure in the Age of Social Media: Endorsements Trump Partisan Source Affiliation When Selecting News Online.” Communication Research 41 (8): 1042-63.

Moore, Don A., and Derek Schatz. 2021. "The three faces of overconfidence." Social and Personality Psychology Compass 11(8): e12331.

Motta, Matthew, Timothy Callaghan, and Steven Sylvester. 2018. "Knowing Less but Presuming More: Dunning-Kruger Effects and the Endorsement of Anti-Vaccine Policy Attitudes." Social Science \& Medicine 211: 274-81.

Nyhan, Brendan, and Jason Reifler. 2010. "When Corrections Fail: The Persistence of Political Misperceptions." Political Behavior 32 (2): 303-30.

_ 2015. "Does Correcting Myths About the Flu Vaccine Work? An Experimental Evaluation of the Effects of Corrective Information." Vaccine 33 (3): 459-64.

Nyhan, Brendan, Ethan Porter, Jason Reifler, and Thomas J Wood. 2019. “Taking FactChecks Literally but Not Seriously? The Effects of Journalistic Fact-Checking on Factual Beliefs and Candidate Favorability." Political Behavior, 1-22. 
Nyhan, Brendan, Jason Reifler, Sean Richey, and Gary L. Freed. 2014. "Effective Messages in Vaccine Promotion: A Randomized Trial." Pediatrics 133 (4): e835-e842.

Ortoleva, Pietro, and Erik Snowberg. 2015. "Overconfidence in Political Behavior.” The American Economic Review 105 (2): 504-35.

Pasek, Josh, Gaurav Sood, and Jon A. Krosnick. 2015. "Misinformed About the Affordable Care Act? Leveraging Certainty to Assess the Prevalence of Misperceptions." Journal of Communication 65 (4): 660-73.

Preece, Jessica Robinson. 2016. "Mind the Gender Gap: An Experiment on the Influence of Self-Efficacy on Political Interest." Politics \& Gender 12 (1): 198-217.

Schaffner, Brian F, and Cameron Roche. 2016. "Misinformation and Motivated Reasoning: Responses to Economic News in a Politicized Environment." Public Opinion Quarterly 81 (1): 86-110.

Rothschild, D., \& Malhotra, N. (2014). Are public opinion polls self-fulfilling prophecies?. Research \& Politics, 1(2), 2053168014547667.

Schlösser, Thomas, David Dunning, Kerri L. Johnson, and Justin Kruger. 2013. "How unaware are the unskilled? Empirical tests of the "signal extraction" counterexplanation for the Dunning-Kruger effect in self-evaluation of performance." Journal of Economic Psychology 39: $85-100$.

Searles, Kathleen, Martha Humphries Ginn, and Jonathan Nickens. 2016. "For Whom the Poll Airs: Comparing Poll Results to Television Poll Coverage.” Public Opinion Quarterly 80 (4): 943-63.

Sheldon, Oliver J., David Dunning, and Daniel R. Ames. 2014. “Emotionally Unskilled, Unaware, and Uninterested in Learning More: Reactions to Feedback About Deficits in 
Emotional Intelligence.” Journal of Applied Psychology 99 (1): 125-37.

Slothuus, Rune, Thomas J. Leeper, and James N. Druckman. 2018. “Motivated

Responses to Political Communications: Framing, Party Cues, and Science Information.” In The

Feeling, Thinking Citizen: Essays in Honor of Milton Lodge, edited by Howard Lavine and

Charles S. Taber, 125-50. Routledge.

Stone, Daniel F. 2019. Unmotivated Bias’ and Partisan Hostility: Empirical Evidence.

Journal of Behavioral and Experimental Economics 79: 12-26.

Svenson, Ola. 1981. “Are We All Less Risky and More Skillful Than Our Fellow

Drivers?” Acta Psychologica 47 (2): 143-48.

Taber, Charles S, and Milton Lodge. 2006. "Motivated Skepticism in the Evaluation of Political Beliefs." American Journal of Political Science 50 (3). Wiley Online Library: 755-69.

Thorson, Emily. 2016. "Belief Echoes: The Persistent Effects of Corrected

Misinformation." Political Communication 33 (3): 460-80.

Uscinski, Joseph E., Casey Klofstad, and Matthew D. Atkinson. 2016. "What Drives

Conspiratorial Beliefs? The Role of Informational Cues and Predispositions." Political Research Quarterly 69 (1): 57-71.

van der Linden, Sander, Anthony Leiserowitz, Seth Rosenthal, and Edward Maibach.

2017. "Inoculating the public against misinformation about climate change." Global Challenges 1(2): 1600008 .

Weeks, Brian E. 2015. "Emotions, Partisanship, and Misperceptions: How Anger and Anxiety Moderate the Effect of Partisan Bias on Susceptibility to Political Misinformation.” Journal of Communication 65 (4): 699-719.

Weeks, Brian E, and R Kelly Garrett. 2014. "Electoral Consequences of Political 
Rumors: Motivated Reasoning, Candidate Rumors, and Vote Choice During the 2008 US

Presidential Election." International Journal of Public Opinion Research 26 (4): 401-22.

Wolak, Jennifer, and Carey E. Stapleton. 2019. "Self-Esteem and the Development of Partisan Identity." Political Research Quarterly, 1065912919851556.

Wood, Thomas, and Ethan Porter. 2019. “The Elusive Backfire Effect: Mass Attitudes'

Steadfast Factual Adherence." Political Behavior 41 (1): 135-63.

Zaller, John R. 1992. The Nature and Origins of Mass Opinion. Cambridge University Press. 


\title{
Online Appendices for: Political Overconfidence Inhibits the Effectiveness of Inoculations Against Misperceptions
}

\author{
Ian G. Anson \\ Associate Professor, \\ University of Maryland, Baltimore County \\ 1000 Hilltop Cir., 305 PUP \\ Baltimore, MD 21250 \\ iganson@umbc.edu
}

October 13, 2021

\section{Table of Contents}

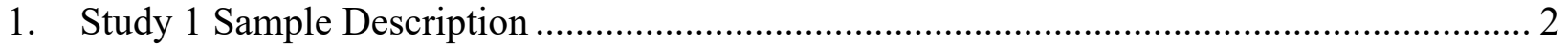

2. Study 1 Questionnaire and Experimental Treatment Descriptions ................................... 3

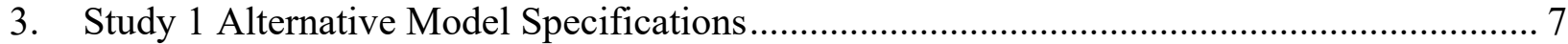

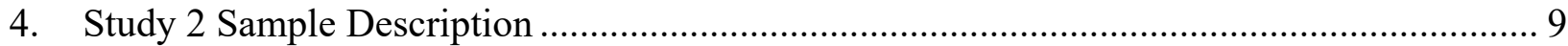

5. Study 2 Pre-Registration Information..................................................................... 10

6. Study 2 Questionnaire and Experimental Treatment Descriptions .................................. 11

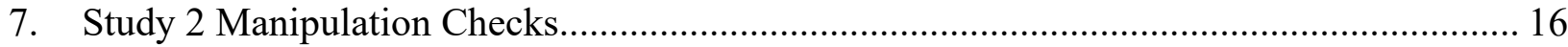

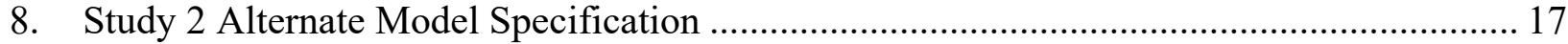

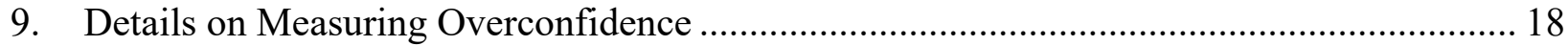

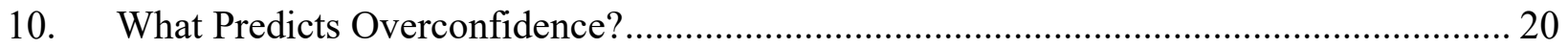

11. Assessment of Political Knowledge Battery ........................................................... 21 


\section{Study 1 Sample Description}

Study 1 was fielded on Amazon MTurk from December 20-21, 2019. The sample include 1,021 adult Americans. Respondents were paid \$1 for their participation. Qualification criteria included U.S. residency, $18+$ age, and $90 \%$ survey completion rate.

As seen in Table A1, the MTurk sample contained far more Democrats $(56.2 \%)$ than Republicans $(28.8 \%)$. This distribution of party affiliation and ideology (the mean ideology was 2.71, slightly more liberal than conservative) is consistent with other MTurk samples. Other demographic information is contained in Table A1 below.

Table A1. Sample Summary Statistics, Study 1

\begin{tabular}{lccccccc}
\hline Statistic & $\mathrm{N}$ & \multicolumn{7}{c}{ Mean } & St. Dev. Min & Pctl(25) Pctl(75) & Max \\
\hline Knowledge(0:5) & 1,021 & 3.258 & 1.346 & 0 & 2 & 4 & 5 \\
Overconfidence & 1,021 & 0.444 & 0.497 & 0 & 0 & 1 & 1 \\
Age & 1,021 & 39.087 & 12.615 & 19 & 29 & 48 & 81 \\
Female & 1,021 & 0.417 & 0.493 & 0 & 0 & 1 & 1 \\
College & 1,021 & 0.578 & 0.494 & 0 & 0 & 1 & 1 \\
Republican & 1,021 & 0.288 & 0.453 & 0 & 0 & 1 & 1 \\
Democratic & 1,021 & 0.562 & 0.496 & 0 & 0 & 1 & 1 \\
Nonwhite & 1,021 & 0.292 & 0.455 & 0 & 0 & 1 & 1 \\
Ideology(1:5) & 1,020 & 2.710 & 1.159 & 1.000 & 2.000 & 4.000 & 5.000
\end{tabular}




\section{Study 1 Questionnaire and Experimental Treatment Descriptions}

\section{Demographics}

- Which best describes your gender?

- Male (0)

- Female (1)

- What is your current age?

- [Year pull-down]

- Which of the following best describes your annual income before taxes?

- Less than $\$ 25,000$ (1)

- $\$ 25,000-\$ 49,999$ (2)

- $\$ 50,000-\$ 74,999(3)$

- $\$ 75,000-\$ 99,999$ (4)

- More than $\$ 100,000$ (5)

- Generally speaking, do you usually think of yourself as a Republican, a Democrat, an Independent, or what?

- Republican (1)

- Democrat (2)

- Independent (3)

- Something else (4)

- (If 1 is selected): Would you call yourself a strong Republican or a not very strong Republican?

- Strong Republican (1)

- Not very strong Republican (2)

- (If 2 is selected): Would you call yourself a strong Democrat or a not very strong Democrat?

- Strong Democrat (1)

- Not very strong Democrat (2)

- (If 3 is selected:) Do you think of yourself as closer to the Republican Party or to the Democratic Party?

- Closer to the Republican (1)

- Closer to the Democratic (2)

- Neither (3)

- What is the highest level of education you have completed?

- Less than high school (1)

- High school graduate/ GED (2)

- Some college (3)

- 2 year degree (4)

- 4 year degree (5)

- Masters degree (6)

- Doctorate (7)

- Professional Degree (JD, MD) (8)

- What racial or ethnic group best describes you?

- White (0)

- Black (1)

- Hispanic (1) 
- $\operatorname{Asian}(1)$

- Native American (1)

- Middle Eastern (1)

- Mixed (1)

- Another racial or ethnic group (1)

- Are you currently registered to vote?

- Yes (1)

- No (0)

- Thinking about politics these days, how would you describe your own political viewpoint?

$\begin{array}{ll}\circ & \text { Very liberal (1) } \\ \circ & \text { Liberal (2) } \\ \circ & \text { Moderate (3) } \\ \circ & \text { Conservative (4) } \\ \circ & \text { Very conservative (5) } \\ \circ & \text { Not sure (NA) }\end{array}$

- Some people seem to follow what's going on in government and public affairs most of the time, whether there's an election going on or not. Others aren't that interested. Would you say you follow what's going on in government and public affairs...?

- Most of the time (4)

- Some of the time (3)

- Only now and then (2)

- Hardly at all (4)

- How many days in the past week did you discuss politics with family or friends? - [0:7]

- In the past 7 days, about how many online surveys or polls (on any topic) have you completed? Please enter a whole number.

Political Knowledge (PK) Battery

- Now we would like you to respond to a series of questions with right and wrong answers. Please try to answer this Political Quiz to the best of your ability. There is NO penalty for incorrect answers. Please do not cheat in any way on this quiz.

- For how many years is a United States Senator elected-that is, how many years are there in one full term of office for a U.S. Senator? [randomize]

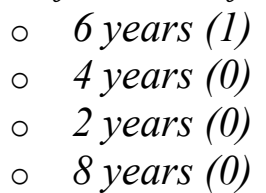

- On which of the following does the U.S. federal government currently spend the LEAST? [randomize]

- Foreign Aid (1)

- Medicare (0)

- National Defense (0)

- Social Security (0)

- Do you happen to know which party currently has the FEWEST members in the U.S. House of Representatives? [randomize] 
- Democrats (0)

- Republicans (1)

- Which political party is more liberal when it comes to healthcare policy? [randomize]

- Democratic Party (1)

- Republican Party (0)

- They are about the same (0)

- Who is the current U.S. Secretary of Energy? [randomize]

- Rex Tillerson (0)

- Rick Perry (1)

- Elaine Chao (0)

- Ben Carson (0)

- Steven Mnuchin (0)

Self-Assessment (SA) Battery

- Next we would like you to rate your own performance relative to everyone who has taken the test. Please use the sliding scale to evaluate your performance on a scale from 0 ("I'm at the very bottom") to 100 ("I'm at the very top"). A rating of 50 indicates that "I'm exactly average". [0:100]

- How would you rate your performance on the test you just took?

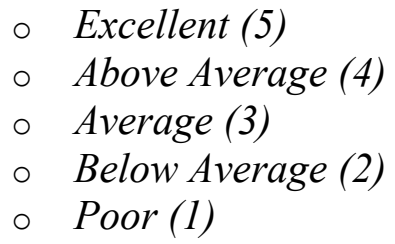

Treatment Preamble

- Next, we would like you to read some statements about politics and current affairs.

- Last month, we asked 1,000 respondents like you to rate these items as either TRUE or FALSE.

- Please take a moment to review these statements, along with the previous respondents' answers.

Treatment Text

Note: Bracketed text indicates [T1/T2] treatment text variations

- "By 2035, there will be no money left to pay out Social Security entitlements to retirees."

- $\quad[31 \% / 6 \%]$ of respondents said this statement was TRUE

- $\quad[69 \% / 94 \%]$ of respondents said this statement was FALSE

- "Violent crime in the United States has increased over the past 10 years."

- [29\%/11\%] of respondents said this statement was TRUE

- $\quad[71 \% / 89 \%]$ of respondents said this statement was FALSE

- "The United States Federal government spends around eighteen percent of its annual budget on aid to foreign countries."

- [38\%/9\%] of respondents said this statement was TRUE

- $[62 \% / 89 \%]$ of respondents said this statement was FALSE 
- "The U.S. Department of Special Programs had an operating budget of $\$ 41$ billion in 2018."

- $[32 \% / 12 \%]$ of respondents said this statement was TRUE

- $\quad[68 \% / 88 \%]$ of respondents said this statement was FALSE

- "Chinese corporate and government entities currently possess more than $50 \%$ of all U.S. government debt."

- $\quad[33 \% / 8 \%]$ of respondents said this statement was TRUE

- $\quad[67 \% / 92 \%]$ of respondents said this statement was FALSE

\section{Battery}

- How accurate would you rate the following statements? Please select a statement ranging from 1 (not at all accurate) to 5 (very accurate)

- "By 2035, there will be no money left to pay out Social Security entitlements to retirees."

- "Violent crime in the United States has increased over the past 10 years."

- "The United States Federal government spends around eighteen percent of its annual budget on aid to foreign countries."

- "The U.S. Department of Special Programs had an operating budget of $\$ 41$ billion in 2018."

- "Chinese corporate and government entities currently possess more than 50\% of all U.S. government debt." 


\section{Study 1 Alternative Model Specifications}

In Study 1, I measure overconfidence using a continuous Confidence Accuracy score with a scale of $[-1,1]$. This scale is derived from taking the difference between a respondent's perceived performance quintile (self-placement) and their observed performance quintile on the PK battery. The results are robust to several additional specifications.

\section{Study 1 Robustness Check 1: Binarized Confidence Accuracy Score}

Study l's results are robust to the use of a binarized version of the Confidence Accuracy score. In this formulation, the scale ignores under-confidence, which is captured in the original Confidence Accuracy score by negative values. In this case, any score of 0 or below is recoded as 0 , while any score above 0 is recoded as 1 .

Table A2. Results of OLS Regression Models Predicting Skepticism [0:1]

\begin{tabular}{|c|c|c|c|c|}
\hline & (1) & (2) & (3) & (4) \\
\hline \multirow[t]{2}{*}{$\mathrm{T} 1$} & $0.059^{* * *}$ & $0.084^{* * *}$ & $0.087^{* * *}$ & $0.085^{* * *}$ \\
\hline & $(0.015)$ & $(0.020)$ & $(0.020)$ & $(0.020)$ \\
\hline \multirow[t]{2}{*}{$\mathrm{T} 2$} & $0.049^{* *}$ & $0.085^{* * *}$ & $0.092^{* * *}$ & $0.090^{* * *}$ \\
\hline & $(0.015)$ & $(0.021)$ & $(0.020)$ & $(0.020)$ \\
\hline \multirow[t]{2}{*}{ Overconfidence $(0 / 1)$} & & -0.018 & $0.054^{*}$ & $0.054^{*}$ \\
\hline & & $(0.022)$ & $(0.025)$ & $(0.024)$ \\
\hline \multirow[t]{2}{*}{ Political Knowledge (1:5) } & & & $0.038^{* * *}$ & $0.039^{* * *}$ \\
\hline & & & $(0.006)$ & $(0.006)$ \\
\hline \multirow{2}{*}{$\begin{array}{l}\text { Knowledge Battery Completion } \\
\text { Time (log) }\end{array}$} & & & & $-0.019^{*}$ \\
\hline & & & & $(0.008)$ \\
\hline \multirow[t]{2}{*}{$\mathrm{T} 1 *$ Overconfidence } & & $-0.061^{*}$ & $-0.069^{*}$ & $-0.068^{*}$ \\
\hline & & $(0.031)$ & $(0.030)$ & $(0.030)$ \\
\hline \multirow[t]{2}{*}{$\mathrm{T} 2 *$ Overconfidence } & & $-0.077^{*}$ & $-0.085^{* *}$ & $-0.082^{* *}$ \\
\hline & & $(0.030)$ & $(0.030)$ & $(0.030)$ \\
\hline \multirow[t]{2}{*}{ Constant } & $0.450^{* * *}$ & $0.459^{* * *}$ & $0.302^{* * *}$ & $0.373^{* * *}$ \\
\hline & $(0.011)$ & $(0.015)$ & $(0.029)$ & $(0.041)$ \\
\hline Observations & 1,017 & 1,017 & 1,017 & 1,017 \\
\hline $\mathrm{R}^{2}$ & 0.016 & 0.049 & 0.083 & 0.088 \\
\hline Adjusted $\mathrm{R}^{2}$ & 0.014 & 0.044 & 0.077 & 0.082 \\
\hline Residual Std. Error & $0.200(\mathrm{df}=1014)$ & $0.197(\mathrm{df}=1011)$ & $0.193(\mathrm{df}=1010)$ & $0.193(\mathrm{df}=1009)$ \\
\hline F Statistic & $\begin{array}{c}8.358^{* * *}(\mathrm{df}=2 \\
1014)\end{array}$ & $\begin{array}{c}10.315^{* * *}(\mathrm{df}=5 \\
1011)\end{array}$ & $\begin{array}{c}15.201^{* * *}(\mathrm{df}=6 \\
1010)\end{array}$ & $\begin{array}{c}13.930^{* * *}(\mathrm{df}=7 \\
1009)\end{array}$ \\
\hline
\end{tabular}




\section{Study 1 Robustness Check 2: Confidence Score Derived from Self-Perception of Mastery}

A second variation in the current analysis involves an alternative specification of overconfidence. While the results presented in-text use self-placement as the basis for the Confidence Accuracy score, it is also possible to use a score based on a respondent's evaluation of their own mastery of the content (ignoring the peer comparison component of self-placement). Results are robust to this alternative specification of confidence:

Table A3. Results of OLS Regression Models Predicting Skepticism [0:1]

\begin{tabular}{|c|c|c|c|c|}
\hline & \multicolumn{4}{|c|}{ Dependent variable: } \\
\hline & \multicolumn{4}{|c|}{ Skepticism } \\
\hline & (1) & (2) & (3) & (4) \\
\hline \multirow[t]{2}{*}{$\mathrm{T} 1$} & $0.059^{* * *}$ & $0.061^{* * *}$ & $0.064^{* * *}$ & $0.063^{* * *}$ \\
\hline & $(0.015)$ & $(0.015)$ & $(0.015)$ & $(0.015)$ \\
\hline \multirow[t]{2}{*}{$\mathrm{T} 2$} & $0.049^{* *}$ & $0.060^{* * *}$ & $0.064^{* * *}$ & $0.063^{* * *}$ \\
\hline & $(0.015)$ & $(0.016)$ & $(0.015)$ & $(0.015)$ \\
\hline \multirow[t]{2}{*}{ Confidence Accuracy [-1:1] } & & -0.020 & $0.108^{* *}$ & $0.103^{* *}$ \\
\hline & & $(0.029)$ & $(0.035)$ & $(0.035)$ \\
\hline \multirow[t]{2}{*}{ Political Knowledge } & & & $0.044^{* * *}$ & $0.044^{* * *}$ \\
\hline & & & $(0.007)$ & $(0.007)$ \\
\hline \multirow{2}{*}{$\begin{array}{l}\text { Knowledge Battery Completion } \\
\text { Time (log) }\end{array}$} & & & & $-0.019^{*}$ \\
\hline & & & & $(0.008)$ \\
\hline \multirow[t]{2}{*}{$\mathrm{T} 1 *$ Confidence Accuracy } & & $-0.091^{*}$ & $-0.099^{*}$ & $-0.097^{*}$ \\
\hline & & $(0.043)$ & $(0.042)$ & $(0.042)$ \\
\hline \multirow[t]{2}{*}{$\mathrm{T} 2 *$ Confidence Accuracy } & & $-0.131^{* *}$ & $-0.136^{* * *}$ & $-0.132^{* *}$ \\
\hline & & $(0.042)$ & $(0.041)$ & $(0.041)$ \\
\hline \multirow[t]{2}{*}{ Constant } & $0.450^{* * *}$ & $0.452^{* * *}$ & $0.299^{* * *}$ & $0.371^{* * *}$ \\
\hline & $(0.011)$ & $(0.011)$ & $(0.027)$ & $(0.041)$ \\
\hline Observations & 1,017 & 1,017 & 1,017 & 1,017 \\
\hline $\mathrm{R}^{2}$ & 0.016 & 0.052 & 0.086 & 0.092 \\
\hline Adjusted $\mathrm{R}^{2}$ & 0.014 & 0.048 & 0.081 & 0.085 \\
\hline Residual Std. Error & $0.200(\mathrm{df}=1014)$ & $0.197(\mathrm{df}=1011)$ & $0.193(\mathrm{df}=1010)$ & $0.193(\mathrm{df}=1009)$ \\
\hline F Statistic & $\begin{array}{c}8.358^{* * *}(\mathrm{df}=2 \\
1014)\end{array}$ & $\begin{array}{c}11.151^{* * *}(\mathrm{df}=5 \\
1011)\end{array}$ & $\begin{array}{c}15.933^{* * *}(\mathrm{df}=6 \\
1010)\end{array}$ & $\begin{array}{c}14.530^{* * *}(\mathrm{df}=7 \\
1009)\end{array}$ \\
\hline
\end{tabular}




\section{Study 2 Sample Description}

Study 2 was performed by recruiting a sample of approximately 1,200 participants on the Lucid Theorem respondent recruitment tool. According to Lucid Theorem, this sample contains a "nationally representative set of survey participants based on age, gender, ethnicity, and region demographics" (lucidtheorem.com/home).

Basic demographics for the Study 2 sample support this assertion. The respondents' demographic information is contained in Table A4 below:

Table A4. Sample Summary Statistics, Study 2 Sample

\begin{tabular}{lccccccc}
\hline Statistic & $\mathrm{N}$ & \multicolumn{1}{c}{ Mean } & St. Dev. & Min & Pctl(25) & Pctl(75) & Max \\
\hline Knowledge(0:5) & 1,209 & 2.327 & 1.137 & 1 & 1 & 3 & 5 \\
Overconfidence & 1,198 & 0.335 & 0.372 & -1.000 & 0.000 & 0.500 & 1.000 \\
Age & 1,209 & 44.142 & 16.479 & 18 & 31 & 57 & 89 \\
Female & 1,209 & 0.492 & 0.500 & 0 & 0 & 1 & 1 \\
Education (1:8) & 1,209 & 4.680 & 1.984 & 1 & 3 & 6 & 8 \\
Republican & 1,209 & 0.318 & 0.466 & 0 & 0 & 1 & 1 \\
Democratic & 1,209 & 0.459 & 0.453 & 0 & 0 & 1 & 1 \\
Nonwhite & 1,209 & 0.278 & 0.448 & 0 & 0 & 1 & 1 \\
Ideology(1:5) & 1,209 & 3.037 & 1.130 & 1 & 2 & 4 & 5 \\
\hline
\end{tabular}




\section{Study 2 Pre-Registration Information}

Study 2 was pre-registered on the osf.io platform. The registration was timestamped on September 21, 2021 at 20:34 GMT -0400, prior to any data collection for Study 2. The preregistration contains information about hypotheses, treatment conditions, randomization, variable coding, and other study details. The link to this registration is as follows:

\section{https://osf.io/v73np}

I report no significant discrepancies between the study pre-registration and the results of Study 2 presented in-text. 


\section{Study 2 Questionnaire and Experimental Treatment Descriptions}

Political Knowledge (PK) Battery

- Now we would like you to respond to a series of questions with right and wrong answers. Please try to answer this Political Quiz to the best of your ability. There is NO penalty for incorrect answers. Please do not cheat in any way on this quiz.

- For how many years is a United States Senator elected-that is, how many years are there in one full term of office for a U.S. Senator? [randomize]
- 6 years (1)
- 4 years $(0)$
- 2 years $(0)$
- 8 years $(0)$

- On which of the following does the U.S. federal government currently spend the LEAST? [randomize]

- Foreign Aid (1)

- Medicare (0)

- National Defense (0)

- Social Security (0)

- Do you happen to know which party currently has the FEWEST members in the U.S. House of Representatives? [randomize]

- Democrats (0)

- Republicans (1)

- Which political party is more liberal when it comes to healthcare policy? [randomize]

- Democratic Party (1)

- Republican Party (0)

- They are about the same (0)

- Who is the current U.S. Secretary of Energy? [randomize]

- Pete Buttigieg (0)

- Deb Haaland (0)

- Nancy Pelosi (0)

- Jennifer Granholm (1)

- Jen Psaki (0)

Self-Assessment (SA) Battery

- Next we would like you to rate your own performance relative to everyone who has taken the test. Please use the sliding scale to evaluate your performance on a scale from 0 ("I'm at the very bottom") to 100 ("I'm at the very top"). A rating of 50 indicates that "I'm exactly average". [0:100]

- How would you rate your performance on the test you just took?

- Excellent (5)

- Above Average (4)

- Average (3)

- Below Average (2)

- Poor (1) 


\section{Treatment 1 (T1)}

- Next, we would like you to read some statements about politics and current affairs.

- Last month, we asked 1,000 respondents like you to rate these items as either TRUE or FALSE.

- $\quad$ Please take a moment to review these statements, along with the previous respondents' answers.

- "By 2035, there will be no money left to pay out Social Security entitlements to retirees."

- $6 \%$ of respondents said this statement was TRUE

- $94 \%$ of respondents said this statement was FALSE

- "Violent crime in the United States has increased over the past 10 years."

- $11 \%$ of respondents said this statement was TRUE

- $89 \%$ of respondents said this statement was FALSE

- "The United States Federal government spends around eighteen percent of its annual budget on aid to foreign countries."

- $9 \%$ of respondents said this statement was TRUE

- $89 \%$ of respondents said this statement was FALSE

- "The U.S. Department of Special Programs had an operating budget of $\$ 41$ billion in 2018."

- $12 \%$ of respondents said this statement was TRUE

- $88 \%$ of respondents said this statement was FALSE

- "Chinese corporate and government entities currently possess more than 50\% of all U.S. government debt."

- $8 \%$ of respondents said this statement was TRUE

- $92 \%$ of respondents said this statement was FALSE 


\section{Treatment 2 (T2)}

\section{YOUR RESULTS}

[If PK1 was Incorrect]: Your answer to Question 1 was Incorrect [If PK2 was Incorrect]: Your answer to Question 2 was Incorrect

[If PK3 was Incorrect]: Your answer to Question 3 was Incorrect [If PK4 was Incorrect]: Your answer to Question 4 was Incorrect [If PK5 was Incorrect]: Your answer to Question 5 was Incorrect

\section{UNDERSTANDING YOUR RESULTS}

Here is how your score ranks when compared to 1,000 other survey respondents who recently took this quiz.

3, 4, or 5 incorrect answers: Below Average

2 incorrect answers: Average

1 or 0 incorrect answers: Above Average

- Please add up your number of INCORRECT answers above. Based on the table above, what was your performance on the political knowledge quiz?

- Below Average (3, 4, or 5 incorrect)

- Average (2 incorrect)

- Above average (1 or 0 incorrect) 


\section{Treatment 3 (T3)}

\section{YOUR RESULTS}

[If PK1 was Incorrect]: Your answer to Question 1 was Incorrect [If PK2 was Incorrect]: Your answer to Question 2 was Incorrect [If PK3 was Incorrect]: Your answer to Question 3 was Incorrect [If PK4 was Incorrect]: Your answer to Question 4 was Incorrect [If PK5 was Incorrect]: Your answer to Question 5 was Incorrect

\section{UNDERSTANDING YOUR RESULTS}

Here is how your score ranks when compared to 1,000 other survey respondents who recently took this quiz.

3, 4, or 5 incorrect answers: Below Average

2 incorrect answers: Average

1 or 0 incorrect answers: Above Average

- Please add up your number of INCORRECT answers above. Based on the table above, what was your performance on the political knowledge quiz?

- Below Average (3, 4, or 5 incorrect)

- Average (2 incorrect)

- Above average (1 or 0 incorrect)

[Page Break]

Next, we would like you to read some statements about politics and current affairs. Last month, we asked 1,000 respondents like you to rate these items as either TRUE or FALSE. Please take a moment to review these statements, along with the previous respondents' answers.

- "By 2035, there will be no money left to pay out Social Security entitlements to retirees."

- $6 \%$ of respondents said this statement was TRUE

- $94 \%$ of respondents said this statement was FALSE

- "Violent crime in the United States has increased over the past 10 years."

- $11 \%$ of respondents said this statement was TRUE

- $89 \%$ of respondents said this statement was FALSE

- "The United States Federal government spends around eighteen percent of its annual budget on aid to foreign countries."

- $9 \%$ of respondents said this statement was TRUE

- $89 \%$ of respondents said this statement was FALSE

- "The U.S. Department of Special Programs had an operating budget of $\$ 41$ billion in 2018."

- $12 \%$ of respondents said this statement was TRUE

- $88 \%$ of respondents said this statement was FALSE

- "Chinese corporate and government entities currently possess more than 50\% of all U.S. government debt."

- $8 \%$ of respondents said this statement was TRUE

- $92 \%$ of respondents said this statement was FALSE 


\section{Battery}

- How accurate would you rate the following statements? Please select a statement ranging from 1 (not at all accurate) to 5 (very accurate)

- "By 2035, there will be no money left to pay out Social Security entitlements to retirees."

- "Violent crime in the United States has increased over the past 10 years."

- "The United States Federal government spends around eighteen percent of its annual budget on aid to foreign countries."

- "The U.S. Department of Special Programs had an operating budget of \$41 billion in 2018."

- "Chinese corporate and government entities currently possess more than 50\% of all U.S. government debt."

\section{Manipulation Checks}

- Next we would like you to rate your political knowledge relative to all Americans. Please use the sliding scale to evaluate your political knowledge on a scale from 0 (I'm at the very bottom) to 100 (I'm at the very top). A rating of 50 indicates that "I'm exactly average." [0:100]

- How would you rate your overall knowledge of politics?
- Excellent (5)
- Above Average (4)
- Average (3)
- Below Average (2)
- Poor (1) 


\section{Study 2 Manipulation Checks}

Study 2 contained two manipulation checks to confirm the effectiveness of the Confidence Adjustment task contained in T1 and T3. Below, I present OLS regression models with these two variables as the $D V$. The first model uses a post-treatment self-placement measure that asks respondents to rate their political knowledge relative to all Americans. The second model uses a post-treatment mastery assessment which asks respondents whether their political knowledge is excellent, above average, average, below average, or poor. Both DVs have been rescaled as continuous $[0,1]$ variables for ease of interpretation.

Table A5. Results of OLS Regression Models Predicting Two Manipulation Check Measures [0:1]

\begin{tabular}{lcccc}
\hline & \multicolumn{4}{c}{ Dependent variable: } \\
\cline { 2 - 5 } & $(1)$ & $(2)$ & $(3)$ & $(4)$ \\
\hline Confidence Adjustment Task & $-0.045^{* *}$ & -0.005 & $-0.055^{* * *}$ & -0.010 \\
Exposure & $(0.015)$ & $(0.020)$ & $(0.014)$ & $(0.018)$ \\
& & $0.237^{* * *}$ & & $0.261^{* * *}$ \\
Confidence Accuracy [-1:1] & & $(0.028)$ & $(0.026)$ \\
& & $-0.115^{* *}$ & & $-0.132^{* * *}$ \\
Task Exposure*Accuracy & & $(0.039)$ & $(0.037)$ \\
& & $0.511^{* * *}$ & $0.626^{* * *}$ & $0.537^{* * *}$ \\
Constant & $(0.011)$ & $(0.014)$ & $(0.010)$ & $(0.013)$ \\
& 1,207 & 1,196 & 1,203 & 1,193 \\
\hline Observations & 0.007 & 0.079 & 0.013 & 0.109 \\
$\mathrm{R}^{2}$ & 0.007 & 0.077 & 0.012 & 0.107 \\
Adjusted $\mathrm{R}^{2}$ & $0.261(\mathrm{df}=1205)$ & $0.251(\mathrm{df}=1192)$ & $0.245(\mathrm{df}=1201)$ & $0.234(\mathrm{df}=1189)$ \\
Residual Std. Error & $9.052^{* *}(\mathrm{df}=1 ;$ & $34.175^{* * *}(\mathrm{df}=3 ;$ & $15.354^{* * *}(\mathrm{df}=1 ;$ & $48.486^{* * *}(\mathrm{df}=3 ;$ \\
F Statistic & $1205)$ & $1192)$ & $1201)$ & $1189)$ \\
\hline Note: & & & ${ }^{*} \mathrm{p}<0.05{ }^{* *} \mathrm{p}<0.01^{* * *} \mathrm{p}<0.001$
\end{tabular}

The results of both manipulation checks confirm that the Confidence Adjustment task reduced self-placement (by 4.5 percentage points, $\mathrm{p}<0.01$ ) and mastery perceptions (by 5.5 percentage points, $\mathrm{p}<0.001)$ in the full sample. In addition, we see that increased overconfidence (represented by positive values in the Confidence Accuracy score) further depresses the posttreatment self-placement and the mastery perception variables among treated respondents. 


\section{Study 2 Alternate Model Specification}

An alternative model specification for Study 2 truncates the sample to consider only respondents who had positive scores on the Confidence Accuracy item (i.e., those respondents were overconfident). I replicate Study 2 using this subsample, which includes 839 of the 1,209 respondents in the sample.

Table A6. Results of OLS Regression Model Predicting Skepticism Among the Overconfident (N=839)

\begin{tabular}{lc}
\hline & Dependent variable: \\
\hline T1: Large Majority Inoculation Message & Skepticism $[0: 1]$ \\
\cline { 2 - 2 } T2: Confidence Adjustment & 0.001 \\
& $(0.015)$ \\
T3: Confidence Adjustment*Inoculation & 0.001 \\
& $(0.015)$ \\
Constant & $0.044^{*}$ \\
& $(0.021)$ \\
\hline Observations & $0.474^{* * *}$ \\
$\mathrm{R}^{2}$ & $(0.011)$ \\
Adjusted $\mathrm{R}^{2}$ & 839 \\
Residual Std. Error & 0.015 \\
F Statistic & ${ }^{*} \mathrm{p}<0.05^{* *} \mathrm{p}<0.01^{* * *} \mathrm{p}<0.001$ \\
\hline Note: & 0.011 \\
\end{tabular}

Results indicate that the combined T3 treatment has a significant positive effect on skepticism of 4.4 percentage points $(p<0.05)$. 


\section{Details on Measuring Overconfidence}

I measure overconfidence through a Confidence Accuracy scale. To do this I relied upon the "self-placement" item included in the SA battery, assessed immediately after the PK battery. The item asks respondents to compare their performance to their peers who had taken the test. It is not the only way to measure overconfidence, however. This scale is strongly correlated with a more standard five-point self-appraisal scale from the SA battery ("How would you rate your performance on the test you just took?') $(\mathrm{r}=0.79)$. Results are robust to the use of either overconfidence measure. I favor the "self-placement" scale, and present it in the findings below, because it accords with the original Dunning-Kruger conceptualization.

Finally, to render the "self-placement" scale into a measure of "over-placement," it was necessary to compare respondents' objective political knowledge with their perceived performance. I subtracted respondents' performance on the initial PK battery (transformed into quintiles) from the "self-placement" scale (measured in quintiles). This transformation can be expressed as follows, with $\widetilde{P K}_{i j}$ reflecting the quintile-transformed knowledge score and $S P_{i k}$ reflecting the five-point self-placement scale:

ConfidenceAccuracy $_{i}=\sum_{k=1}^{5} S P_{i k}-\sum_{j=1}^{5} \widetilde{P K}_{i j}$

The resulting scale has a theoretical range of $[-4,4]$. Positive values on the scale are instances in which objective performance exceeded one's quintile score, while negative values indicate overconfidence. Values of zero indicate respondents who accurately assessed their performance. This measure was rescaled in both studies to a $[-1,1]$ variable for ease of interpretation. Study 1 result showed that $44.5 \%$ of the respondents had overestimated their general political knowledge 
by at least one quintile, $29 \%$ had an accurate self-appraisal relative to other test-takers, and the rest $(26.5 \%)$ were underconfident, having placed themselves in a lower performance quintile than their performance merited. In Study 2, 10.6\% were underconfident, $18.1 \%$ had accurate self-appraisals, and the remainder of respondents $(839$, or $69.4 \%)$ were overconfident to at least some extent. 


\section{What Predicts Overconfidence?}

In this section, I provide a glimpse at the predictors of overconfidence, in an effort to better understand its properties. In Table A7, based on data from Study 1, I demonstrate that overconfidence is influenced in a positive direction by political knowledge and formal education (as might be expected). In addition, females are less overconfident than males on average, a well-known finding in the literature on confidence and personality.

Table A7. Results of Logistic Regression Model Predicting Overconfidence, Study 1

Dependent variable:

Overconfidence $[0,1]$

Knowledge

$-2.748^{* * *}$

(0.174)

Age

$-0.082$

$\mathrm{Age}^{2}$

0.001

(0.0005)

Female

$-0.516^{* *}$

(0.165)

Completed College

$0.427^{* *}$

(0.161)

Republican

Democrat

$-0.124$

Nonwhite

(0.176)

Ideology

0.143

Constant

$2.533^{* *}$

(0.927)

Observations

1,020

Log Likelihood

$-503.451$

Akaike Inf. Crit.

$1,026.903$

Note:

$p<0.05 ; p<0.01 ; p<0.001$ 


\section{Assessment of Political Knowledge Battery}

Below, I provide an exploratory factor analysis of the five-item knowledge battery presented to respondents in Study 1's PK battery. The PK battery was used to create the measures of overconfidence used in the study, and as such, it is important to verify that the items are all indicative of objective political knowledge. In Figs. A3 and A4, below, I present a Scree plot and a Biplot of the knowledge battery.

Fig. A1: Scree Plot, Factor Loadings for Question Battery

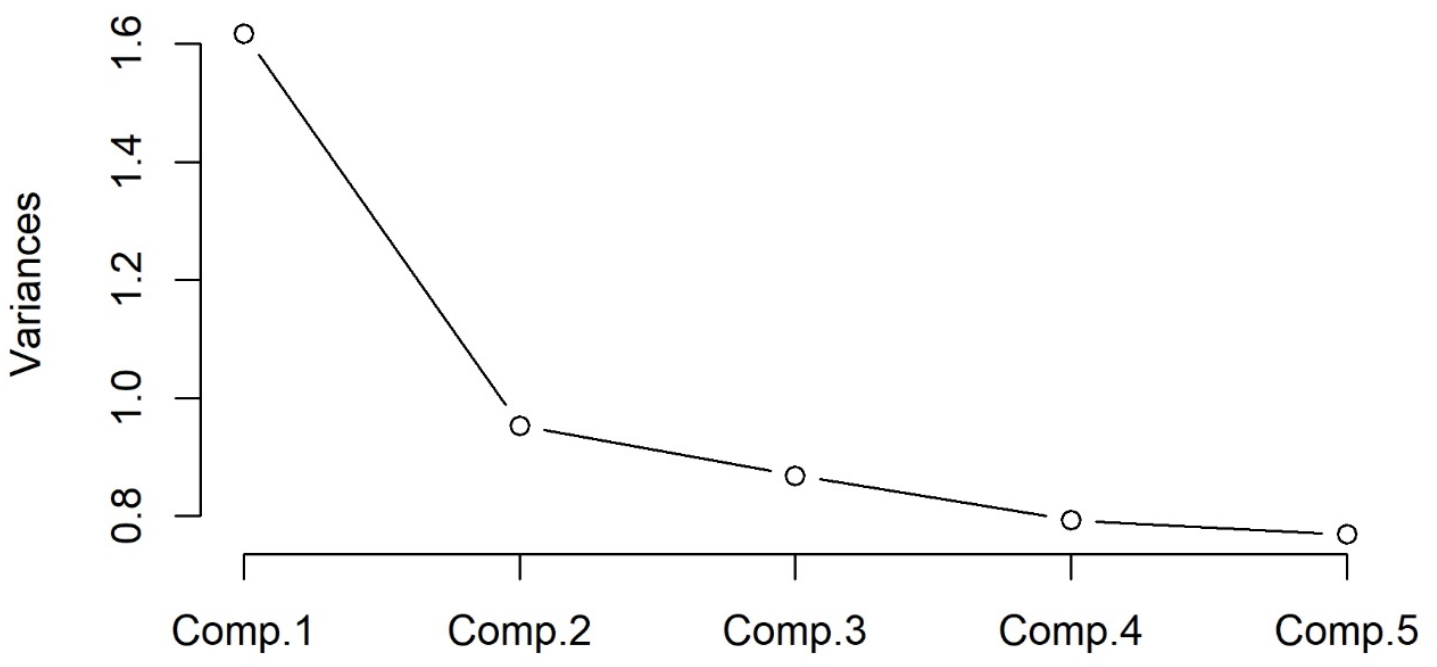


Fig. A2: Biplot, Factor Loadings for Question Battery

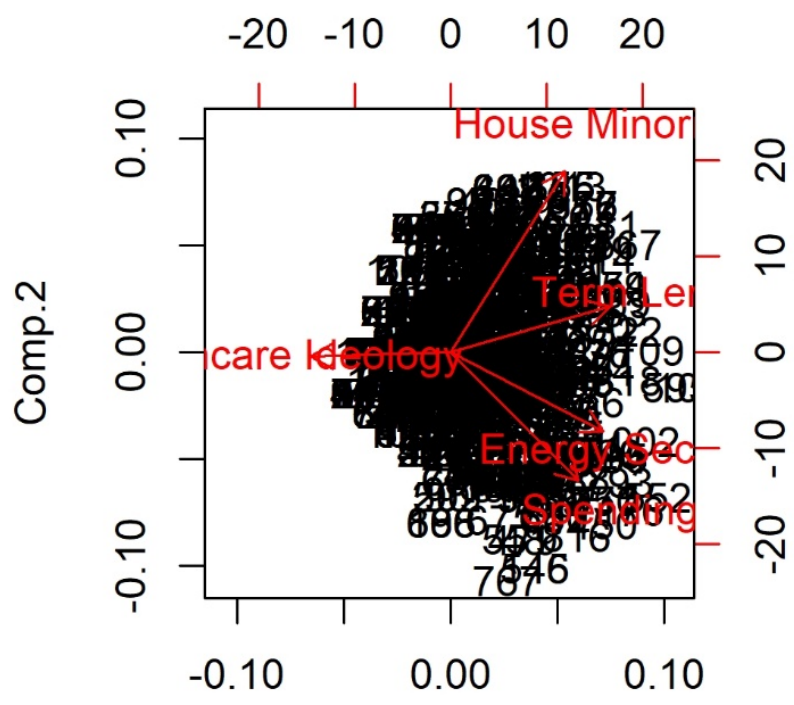

Comp. 1

Figs. A1 and A2, consistent with the results shown in Anson (2018), show that the knowledge battery items tend to hang together fairly well as an additive scale. The Scree plot identifies one major factor rather than multiple. The weak second dimension of the scale appears to apply to the question about the comparative ideology of the two major political parties. As ideological reasoning is a distinct concept in the literature on political sophistication relative to recall of basic facts and current events, the results seen in Fig. A4 make some degree of intuitive sense. 